\title{
EL PANATENAICO DE ISÓCRATES: \\ 3- LAS CARTAS A LOS MACEDONIOS
}

\author{
JUAN SIGNES CODOÑER \\ Universidad de Valladolid
}

Isocrates' four letters to the Macedonian rulers (II, III, IV and V) belong to the latter years of his life and are therefore of great importance for a right understanding not only of his political attitude towards Philip II, but also of the purpose and meaning of the Panathenaicus. All four letters are to be regarded as genuine, although letter IV to Antipater (to be dated 340) was perhaps written under the guidance of Isocrates by the person he recommended, a certain Diodotos. Letter II is to be dated earlier than spring 344 - when Philip's intervention in the Thessalian affairs took place causing unrest in Athens. Letter V to Alexander the Great was written between 343-342 and raised no political issue: It reflects only Isocrates' concern about the education of the Macedonian prince. Letter III, which eulogized so heavily Philip's policy was by no means written after the Athenian defeat at Chaironeia, because it discredits Isocratean patriotism and contradicts the ancient biographical tradition which speaks unanimously about the suicide of our orator a few days after the battle. No letter was therefore written after the Panathenaicus. Isocrates didn't write openly to Philip about politics after spring 344.

El corpus epistolar que bajo el nombre de Isócrates ha llegado hasta nosotros contiene un total de nueve cartas de las que cuatro (cartas II, III, IV y V) están dirigidas a gobernantes macedonios, todas ellas escritas con posterioridad a la redacción del $A$ Filipo en el año 346. Considerando que después de esta fecha el único discurso que se nos conserva de Isócrates es el Panatenaico, estas cuatro cartas nos ofrecen por lo tanto un testimonio crucial para verificar la validez de la interpretación que hice de este discurso en las 
dos entregas anteriores de este estudio ${ }^{1}$. Por ello es preciso dedicar a estas cartas un estudio detallado e individualizado que tenga en cuenta sus problemas de autenticidad y datación, en torno a los cuales hubo un intenso debate a fines del XIX y principios del XX que no ha tenido apenas continuidad en épocas más recientes.

\section{La primera carta a Filipo (II)}

Se trata de la carta más larga de nuestro orador. En ella Isócrates se dirige al rey pidiéndole disculpas por dirigirse a él de nuevo, aunque no sea para darle consejos como en ocasiones anteriores, sino para interesarse por lo que le ha sucedido, ya que es algo que ha puesto en riesgo su vida (§1-2). Según nos dice, el rey, para demostrar su valor, ha corrido un riesgo innecesario e impropio de su condición, pues si hubiese muerto en combate, no sólo habría perdido su vida, sino perjudicado sus planes (§3-4). En otros estados como Atenas, Esparta y Persia los gobernantes siempre han sido protegidos de los peligros que acechan en combate, pues su muerte perjudica al estado (§5-8), por lo que Filipo tendría que tener estos ejemplos presentes y mantenerse vivo para alcanzar una gloria que sólo a él está reservada (§9-10). Objetivo de Filipo, continúa nuestro orador, no deben ser guerras difíciles y sin prestigio contra los bárbaros, pues basta con controlar sus fronteras, sino la guerra contra el rey persa $(\S 11)$. Isócrates se lamenta de no haberle enviado la carta antes de que saliera en campaña para que así el rey hubiera sido precavido y evitado la herida $(\$ 12)$ y aunque quiere concluir aquí este escrito a fin de no convertir en discurso una simple carta $(\S 13)$, se extiende un poco más para señalar a Filipo que no haga caso de las críticas que contra él dirigen ciertos oradores que manipulan al pueblo (§14-15) y siga manteniendo la alianza con Atenas, pues aunque esta ciudad ha cometido errores, sigue siendo la que más útil resultará a Filipo en su lucha contra los bárbaros (§16-18), mucho más útil desde luego que el recurso a mercenarios (§19). Insta a Filipo a que tenga con Atenas el mismo prudente comportamiento que tuvo con los tesalios y evite el uso de la fuerza (\$20-21) y termina la carta quejándose de la mala reputación que él mismo tiene entre

1 «El Panatenaico de Isócrates: 1 - El excursus de Agamenón», EMERITA 64, 1996, pp. 137-156 y «El Panatenaico de Isócrates: 2 - Tema y finalidad del discurso», EMERITA 66, 1998, pp. 67-94. 
determinados círculos atenienses (\$22-23) e instando de nuevo a Filipo a actuar en favor de los griegos ( $\$ 24)$.

La carta, cuya autenticidad no ha sido nunca cuestionada, es posterior a la redacción del discurso A Filipo del 346 ya que en su comienzo Isócrates recuerda que ya anteriormente ha dado consejos al rey sobre qué es lo que le

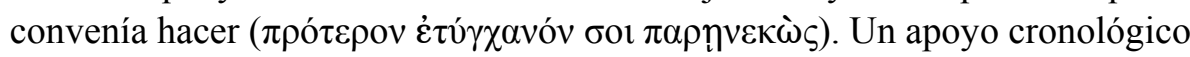
para precisar más su datación lo da el propio motivo de la carta, que Isócrates declara haber escrito preocupado por la salud de Filipo y por el hecho de que asuma riesgos innecesarios que le pueden causar la muerte. En §11 Isócrates insta incluso al rey a que no se empeñe excesivamente en las guerras que ahora lleva a cabo contra los bárbaros y que se limite simplemente a asegurar su territorio contra ellos, pues su principal objetivo debe ser la guerra contra el persa. Por el tenor de lo escrito en $\$ 12$ queda claro que es justamente en el curso de esta campaña cuando Filipo ha corrido un gran riesgo que ha estado a punto de costarle la vida. Se trata evidentemente de alguna de las graves heridas que recibió Filipo a lo largo de su vida, sin duda, como todos los estudiosos conceden, de la que Filipo recibió en la pierna derecha en el curso de la sangrienta campaña contra Pleurato, el rey de los ardieos, un pueblo ilirio de la costa dálmata. De ella y de otras heridas que recibió el rey nos informa Dídimo en su comentario a Demóstenes XI. $22^{2}$. Otras heridas que recibió Filipo en los años 354 y 339 no entran aquí en consideración por salirse del marco cronológico que marcan, como veremos enseguida, las indicaciones de la carta. La datación de la carta depende pues directamente de la datación de la campaña de Filipo contra los ardieos, que sucedió inmediatamente a la campaña contra los dardanios. Sin embargo estamos mal informados de ambas campañas pues nuestras fuentes, especialmente Diodoro Sículo (XVI 69) y Justino (VIII 6), son confusas acerca del momento en el que tuvieron lugar.

Benno von Hagen y casi simultáneamente Eduard Meyer no tuvieron duda de que las campañas contra los ilirios tuvieron lugar en el 344 considerando que precedían a la que Filipo llevó a cabo en Tesalia en otoño de ese mismo año ${ }^{3}$. La carta de Isócrates tenía por lo tanto que ser posterior a esta fecha, por

\footnotetext{
2 El comentario se conserva en un papiro hallado en Egipto: H. Diels - W. Schubart (eds.), Dydimi de Demosthene commenta, Leipzig, 1904, cols. 12, lín. 40 a 13 lín. 12.

3 B. von Hagen, «Isokrates und Alexander», Philologus 67, 1908, pp.113-133, aquí pp. 121-124 y E. Meyer, «Isokrates' zweiter Brief an Philipp und Demosthenes' zweite Philippika», en Sitzungsberichte der preußischen Akademie der Wissenschaften 1909, pp.
} 
lo que habría sido escrita bien a finales del 344 o incluso, como pensaba von Hagen, a principios del 343. Esta opinión, desde que fue asumida por Georges Mathieu en su edición de Belles Lettres, se convirtió en communis opinio prácticamente hasta hoy entre $\operatorname{los}$ filólogos ${ }^{4} \mathrm{y}$ es aceptada sin discusión en recientes ediciones de Isócrates ${ }^{5}$. No obstante entre los historiadores se ha propuesto desde hace años el año 345 como fecha alternativa para las campañas ilirias de Filipo. La propuesta, que cuenta con algún antecedente a principios de siglo ${ }^{6}$, fue defendida de nuevo por G.L. Cawkwell en 1963 en un artículo dedicado a reconstruir el escenario político ateniense tras la paz de Filócrates del $346^{7}$. Cawkwell discutía la datación de la embajada del bizantino Pitón, enviado por Filipo II a Atenas para intentar defender al rey de las acusaciones de romper la paz y perjudicar los intereses de Atenas. Según la propuesta de este autor, la embajada de Pitón no habría tenido lugar en el 343, como se pensaba unánimente hasta entonces, sino un año antes, en el 344. Una prueba de ello sería la propia II Filípica de Demóstenes, que se habría escrito precisamente para responder a las acusaciones de la legación macedonia de Pitón. Para Cawkwell era necesario en consecuencia retrasar la fecha de la carta II de Isócrates hasta el 345, puesto que las observaciones hechas por el orador en la carta II.14-15, minimizando las críticas de los atenienses a Filipo y calificándolas de calumnias, son absolutamente inapropiadas («inapposite») en el ambiente caldeado que se vivió en Atenas un año después como consecuencia de la embajada. Cawkwell encontraba un apoyo a su propuesta de datación en el hecho de que la campaña contra los arieos en la que fue herido Filipo muy bien pudiera haber tenido lugar en el 345 , ya que: 1) todos los estudiosos están de acuerdo en que la mención de las dos campañas ilirias en Diodoro XVI.69.7 dentro del año ático 344/343 es muy tardía y fruto de un error al ordenar su narración de los hechos de esos años; 2) parece imposible que Filipo pudiera desarrollar en la primera mitad

758-779 (recogido en Kleine Schriften, vol. II, Halle, 1924, pp. 101-129).

4 G. Mathieu, «Lettres», en G. Mathieu - É. Brémond, Isocrate. Discours, vol. IV, París, 1962, pp. 174-176 y G. Mathieu, Philippe et lettres a Philippe, à Alexandre et à Antipatros, texte et traduction avec une intr. et des notes, París, 1924, pp. 37-41.

5 Cf. J.M. Guzmán Hermida (trad.), Isócrates. Discursos, Madrid, 1980, vol. II p. 273. Yo mismo la acepté como válida en EMERITA 1998, p. 80, nota 32, antes de someter la cuestión a un examen detallado.

6 Cf. Mathieu, Philippe..., p. 37 nota 256.

7 G.L. Cawkwell, «Demosthenes' policy after the Peace of Philocrates. I», CQ 13, 1963, pp. 120-138. 
del año 344 dos campañas tan complejas ${ }^{8}$ como las realizadas contra los dardanios y los arieos antes de marchar sobre Tesalia; 3) no consta expresamente en ninguna fuente que Filipo haya realizado campaña alguna en el año 345 ya que la fundación de colonias que le atribuyen las fuentes «would not have required Philip's presence or the use of his whole military power».

Los argumentos de Cawkewll en lo que respecta a la datación de la embajada de Pitón no han sido siempre aceptados por algunos de los mayores especialistas del periodo ${ }^{9}$, pero su idea de que las dos campañas ilirias deben datarse en el 345 fue retomada por Griffith, que la defendió con varios argumentos de manera convincente ${ }^{10}$. La propuesta de Griffith, con matices, parece haberse convertido en communis opinio entre los historiadores ${ }^{11}$. Ello significa que la carta de Isócrates para estos historiadores pudo haber sido escrita ya en el 345 o, a lo más tardar, a comienzos del 344, pues aunque Isócrates escribe al rey con motivo de la herida que acaba de sufrir, era necesario un cierto tiempo antes de que la noticia llegase a Atenas desde la región de los arieos donde estaba el rey de campaña. En cualquier caso, Isócrates escribe mucho tiempo antes de la redacción de la II Filípica en el otoño del 344, que marca un primer punto de inflexión en el camino hacia la guerra entre Atenas y Macedonia después de firmada la paz de Filócrates en el 346. Esta datación encaja perfectamente con el duro tono empleado en esta epístola abierta a la hora de criticar a los enemigos atenienses de Filipo, quizás difícilmente explicable en el ambiente político de fines del 344.

Otro aspecto que ayuda a fijar la datación de la carta es la mención que se

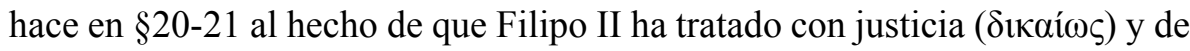
manera adecuada ( $\sigma \nu \mu \varphi \varepsilon \rho o ́ v \tau \omega \varsigma)$ a los tesalios. Meyer pensó que esta indicación se refería a la intervención en Tesalia llevada a cabo por Filipo en el 344,

$8 \quad$ El propio Isócrates califica estas guerras de $\chi \alpha \lambda \varepsilon \pi$ oú $\varsigma$ en carta III.11.

9 J.R. Ellis acepta la fecha de la embajada en el 344 (The Cambridge Ancient History, vol. VI: The Fourth Century B.C., Cambridge 1994, p. 766) mientras que N.G.L. Hammond sigue con la datación en el 343 (N.G.L. Hammond, Philip of Macedon, Londres 1994, p. 106) y G.T. Griffith piensa que pudo tener lugar en el invierno del 344/343 (N.G.L. Hammond G.T. Griffith, A History of Macedonia, vol. II: 550-336 B.C., Oxford 1979, p. 724).

10 G.T. Griffith, «Illyrian War (?) 345», en Hammond - Griffith, Hist. of Macedonia, ob. cit., pp. 469-474.

${ }_{11}$ J.R. Ellis en Cambridge An. Hist., vol. IV, ob. cit., pp. $762-763$ opta por el 345 para las campañas ilirias, pero Hammond, Philip..., ob. cit., pp. 115-117 aunque se inclina por el 345 para su comienzo, no descarta que se prolongasen en el 344. 
que databa justamente después de las campañas ilirias de ese año. Sobre la actuación de Filipo en Tesalia en el 344 nos informan diversas fuentes ${ }^{12}$, que hablan de la deposición de tiranos de algunas ciudades tesalias y la imposición de un nuevo orden más centralizado controlado por guarniciones macedonias. Podría pensarse que las palabras de Isócrates puedan aplicarse a los cambios acaecidos en el 344, pero ya el propio Meyer advirtió que en el $A F i$ lipo 20, escrito en el 346, Isócrates hablaba en términos similares del tratamiento dado por Filipo a los tesalios, gracias al cual el rey había conseguido su fidelidad. Filipo, según escribía Isócrates en el 346, había conseguido gra-

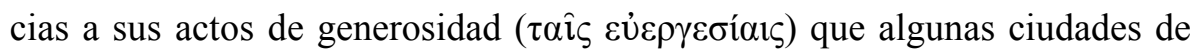

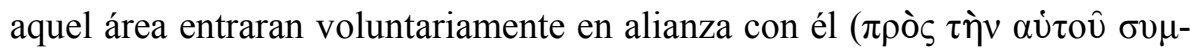
$\mu \alpha \chi(\alpha v)$, mientras que sometió por la fuerza a aquellas que le habían causado daño ${ }^{13}$. En realidad, Filipo estaba interviniendo en los asuntos de Tesalia desde el 353. Los sucesos del 344 fueron motivados precisamente por una sublevación de ciudades como Feras y Larisa contra el statu quo marcado por los macedonios en los años previos y sólo suponen el final de un proceso de creciente intervencionismo del rey macedonio en la región. Es por lo tanto evidente que las alusiones a Tesalia de la carta III no tienen por qué referirse los sucesos del 344 y pueden haber sido escritas años antes, como el pasaje del $A$ Filipo $^{14}$. Si Isócrates se hubiera referido en su carta III a la intervención tesalia del 344, quizás hubiéramos esperado de él una postura de apoyo menos entusiasta a la política de Filipo, considerando que su contemporáneo Demóstenes escribía justamente en el año 344 duras palabras respecto al definitivo sometimiento de Tesalia por los macedonios (II Filípica 22), que sabemos acantonaron allí guarniciones de soldados (III Filípica 12) ${ }^{15}$. Si consideramos además que Isócrates en su carta III. 20 escribe que la prudente política que Filipo ha seguido con los tesalios es la misma que debe adoptar con

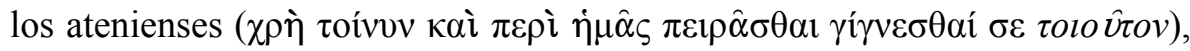
parece bastante difícil pensar que nuestro orador pueda tener en mente los su-

12 Diod. Sículo XVI.69.7-8, Polieno IV.2.19, Dem. VI.22, VIII.62 y XIX.259-260 etc.

13 Meyer, ob. cit. (nota 3), p. 109.

14 Hammond, Philip..., ob. cit, p. 118 parece ignorar este pasaje del A Filipo y considera que la carta III de Isócrates se refiere a los sucesos tesalios del 344, algo que confirma en p. 117 cuando indica que Isócrates la escribió en el 344. Sin embargo en p. 105 señala que Isócrates escribió su carta III «in late 345 or early 344», tal como yo defiendo, sin darse cuenta de la contradicción en la que incurre.

15 Hammond - Griffith, Hist. of Macedonia..., ob. cit., pp. 528-534. 
cesos del $344^{16}$. Estas consideraciones sirven pues para mantener la datación de la carta en el 345 o, a lo más tardar, a principios del 344 cuando todavía no se sabía nada de los planes de intervención de Filipo en Tesalia ${ }^{17}$.

Las alusiones a atenienses que critican la política de Filipo encajan quizás mejor, como ya sugirió Cawkwell, en el contexto anterior al verano del 344 que en el posterior a esta fecha, donde la progresiva hostilidad de los atenienses a la potencia macedonia hubiera quizás llevado a Isócrates a formular la carta de otra manera. Así, la ya mencionada referencia a los que calumnian a Filipo en $\S 15$, una crítica directa a la labor que estaba realizando Demóstenes por esas fechas, hubiera sido quizás expesada de forma más prudente. Por otra parte, ya indicamos en la parte segunda de este estudio que la progresiva hostilidad de Atenas hacia Filipo acabó perjudicando al propio Isócrates y fue una de las causas que le impulsaron a escribir el Panatenaico para vindicar su patriotismo. Las afirmaciones del orador en $\$ 22$ de que su prestigio no es bueno entre el pueblo y aquellos que carecen de una opinión sólida

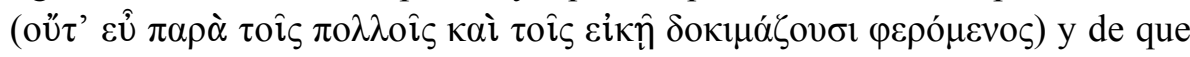
incluso no se entienden sus opiniones y se le tiene envidia ( $\dot{\alpha} \gamma v o o v ́ \mu \varepsilon v o \varsigma$ ú $\pi$ ' $\alpha u ̉ \tau \hat{\omega} v \kappa \alpha \grave{\imath} \varphi \theta$ ovoú $\mu \varepsilon v o \varsigma)$ son precisamente las que encontramos en el comienzo del Panatenaico, donde Isócrates se queja amargamente de la incomprensión de muchos de sus conciudadanos. Que la coincidencia no es casual lo prueba otro detalle. En §16 Isócrates afirma que también Atenas, a pesar de ser la ciudad que más beneficios ha procurado a todos los griegos, ha co-

16 Pace M.M. Markle, «Support of Athenian intellectuals for Philip: a study of Isocrates' Philippus and Speusippus' Letter to Philip», JHS 96, 1976, pp. 80-99, que partiendo de una datación de la carta en el 344 considera que de acuerdo con este pasaje Isócrates estaba aconsejando a Filipo que «ganase el apoyo de Atenas apoyando por todos los medios a los partidarios de Macedonia y aplastando por la fuerza todas las facciones que se le opusieran» (p. 88). Parece difícil que Isócrates pudiera expresarse públicamente en esos términos frente a su ciudad sin correr el riesgo de ser considerado un traidor, una circunstancia que el propio Markle señala en la primera parte de su estudio al indicar que el $A$ Filipo de Isócrates estaba esencialmente dirigido a sus conciudadanos (pp. 81-85).

17 El hecho de que en $\$ 18$ Isócrates indique que si tuviese a Atenas como aliado no encontrarían en ella ningún refugio ( $\dot{\alpha} \pi \circ \sigma \tau \rho \circ \varphi \eta v)$ personas que están ahora sometidas a él, puede referirse a los focios refugiados en Atenas al finalizar la III Guerra Sagrada en el verano del 346 (Dem. V.19). Si esta inferencia es correcta, creo que ello sería otro motivo para datar la carta más cerca del año 346 que del 344. Más difícil de interpretar es el hecho de que la carta II.11 contenga reflexiones sobre bárbaros y persas muy similares a las de la carta III.5, pues no podría decirse cuál de los dos pasajes pudo escribirse primero. 
metido errores, pues ni siquiera los dioses están faltos de ellos. En el Panatenaico 64 Isócrates repite la misma indicación y añade "ya hice mención antes

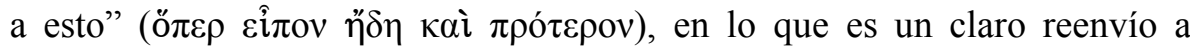
nuestro pasaje. Estas consideraciones nos permiten sospechar que las reflexiones que se hace Isócrates en la carta coinciden totalmente con las inquietudes que le llevaron por los años 344-342 a escribir finalmente el Panatenaico. La concreción de las indicaciones, las alusiones al clima que se vivía entonces en Atenas, el propio estilo de la carta, así como el reenvío desde el Panatenaico a ella, demuestran que estamos ante una carta genuina de Isócrates.

\section{La carta a Antípatro (IV)}

Más problemas de autenticidad ha despertado por el contrario la carta IV dirigida por Isócrates a Antípatro, embajador macedonio ante Atenas en dos ocasiones: en el 346 con motivo de la paz de Filócrates y en el 338 para negociar la paz que sucedió a la batalla de Queronea. En la carta nuestro orador recomienda ante Antípatro a un personaje llamado Diodoto y a su hijo, sobre los que nada sabemos y no encierra más alusión a las circunstancias históricas que la que hace Isócrates al comienzo cuando señala que le resulta peligroso enviar una carta a Macedonia ahora que está en guerra con Atenas. La carta tuvo por lo tanto que escribirse una vez estallada la guerra entre Atenas y Filipo II en el 340. Isócrates no dirige además a Antípatro ninguna reflexión, al contrario de lo que ocurre con los destinatarios de las cartas VII y VIII que también contienen recomendaciones, por lo que cabe suponer que ya había tenido previamente trato con él, probablemente en el 346.

Son muchos los autores que han cuestionado la autenticidad de la carta. El primero fue Bruno Keil por razones fundamentalmente de estilo que nadie hasta la fecha, como veremos, ha podido refutar ${ }^{18}$. Según constató este estudioso, hay en la carta muchas expresiones que no aparecen en el resto de

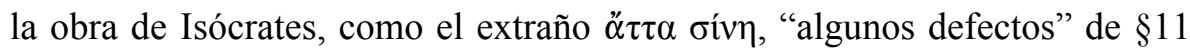

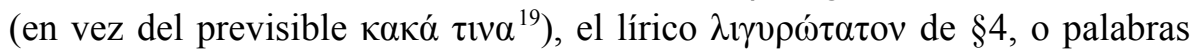

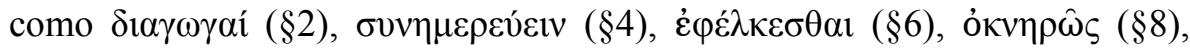

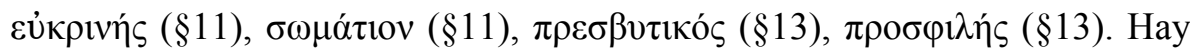

18 B. Keil, Analecta Isocratea, Praga - Leipzig, 1884, pp. 143-145.

$19 \alpha \ddot{\alpha} \tau \tau \alpha$ sólo aparece excepcionalmente en Isócrates ante vocal para evitar el hiato. 
además expresiones o giros realmente poco afortunados e impropios de Isó-

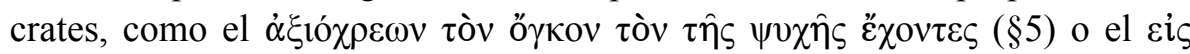

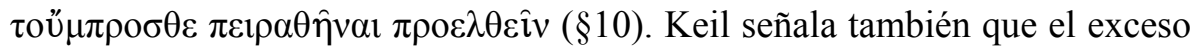
de comparaciones que encontramos en la carta es «ab Isocrate plane alienum», como cuando en $\S 8$ se dice que las dificultades que tuvo Diodoto con sus anteriores patrones (unos $\delta v v \alpha \sigma \tau \alpha i$ de Asia) le disuadieron de acercarse a Antípatro, del mismo modo que aquél que ha padecido una tormenta en el mar no se atreve ya a navergar; o también cuando en §10-11 señala que Diodoto considera que entrar al servicio de Antípatro es como participar en un certamen atlético, aunque reconoce que carece de la fuerza para ganar la corona $^{20}$. Finalmente, entre otras observaciones, Keil señala que es improcedente enumerar todos los problemas que tuvo Diodoto en Asia con sus ante-

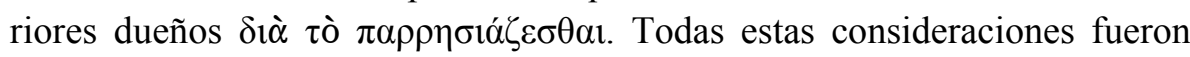
valoradas por Keil en su conjunto como decisivas para negar la autoría de la carta a Isócrates.

Keil desautorizaba además la hipótesis de Blass de que las peculiariades estilísticas de la carta, que él ya había observado, se explicaban por su carácter privado y confidencial («vertraulich») ${ }^{21}$. Según Blass, Isócrates no había pretendido hacer un «Schaustück», sino una carta de recomendación privada y por ello descuidó su estilo, lo que hacía la carta «muy interesante por su singularidad». Para Keil esto es inconcebible, puesto que el estilo usado es en ocasiones más poético que sencillo y por otra parte, según decía, «expresiones de ese tipo no creo que sean tanto propias de un discurso familiar (pues pensamos que no se encuentran en cartas familiares), como de un orador que pretende hacer un despliegue de sus capacidades sin que ello venga a cuento».

La polémica continuó en los años siguientes sin que se añadieran nuevos argumentos al problema, sino sólo matices y precisiones. Wilamowitz apoyó las conclusiones de Keil en 1892 y pensó incluso que Diodoto y su hijo pudieron haber compuesto la carta mucho después de muerto Isócrates ${ }^{22}$. Pero

20 Una comparación similar en Antídosis 301, pero en este caso pertinente, ya que Isócrates critica como excesivos los elogios que se tributan a los atletas.

21 F. Blass, Die attische Beredsamkeit., vol. II: Isokrates und Isaios, Leipzig, 1892, $2^{\mathrm{a}}$ ed (reimpr. Hildesheim, 1962), p. 329 - Keil manejó la primera edición de la edición de Blass, aparecida en 1874 y recoge también en su enumeración algunas de las observaciones de éste sobre el estilo de la carta.

22 U. von Wilamowitz-Moellendorf, Aristoteles und Athen, Berlín, 1893, vol. II., pp. 393-394. 
Blass en los Nachträge del vol. III.2 de su Attische Beredsamkeit insistió, replicando a Wilamowitz, en la idea de que la carta IV era especial por el hecho de no haber sido publicada, a diferencia de las ocho restantes que sí lo fueron, lo que hacía inútil el análisis de Keil ${ }^{23}$. Wilamowitz replicó de nuevo a Blass en un artículo aparecido en $1898^{24}$, en el que insistía en los argumentos de Keil. Wilamowitz se centraba en el carácter inapropiado de las palabras $\lambda$ ıropós, que él consideraba vulgar con independencia de que apareciese en el Cinegético de Jenofonte ${ }^{25}$, y ö $\tau \tau \alpha$ una forma ática, pero evitada por Isócrates, Tucídides y los trágicos. Wilamowitz se extrañaba además de que Isócrates no utilizara el mismo estilo en las otras cartas confidenciales conservadas (refiriéndose probablemente a las cartas VII y VIII) y consideraba finalmente que no podía ser privada ni confidencial una carta con una cuidada composición rítimica como la de la carta IV. Blass replicó una vez más a Wilamowitz en otro artículo aparecido al año siguiente ${ }^{26}$ en el que insistía que $\lambda$ uyvoós podía ser usado en prosa ática porque aparecía en el Cinegético de Jenofonte y apuntaba la posibilidad de que el uso de $\ddot{\alpha} \tau \tau \alpha$ y otras palabras inapropiadas para Isócrates de esta carta IV fueran introducidas por nuestro orador en el discurso recogiendo las propias palabras de Diodoto. Blass defendía de nuevo la posibilidad de que se hubieran perdido muchas otras cartas privadas de Isócrates con un estilo sencillo y similar al de la carta IV, pero no consideraba la cuestión de la confidencialidad de las cartas VII y VIII, también cartas de recomendación. La discusión, simplificada en torno al valor que se debe dar a

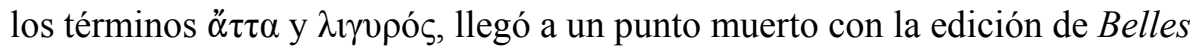
Lettres de Georges Mathieu, para el que la carta era auténtica de Isócrates, como defendía Blass, y no podía ser comparada a otras del orador por su

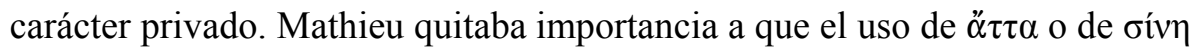
fuese significativo como para denegar la autoría del discurso a Isócrates. Descalificaba además la hipótesis de Wilamowitz de que la carta hubiera sido falsificada por Diodoto a la muerte de Isócrates, pues se preguntaba con razón: «De quelle utilité aurait pu être, plusieurs années après la mort d'Isocrate, une lettre de recommandation attribuée à celui-ci? ${ }^{27}$. Las ideas de Ma

23 Blass, Die attische Beredsamkeit, vol. III.2, p. 382-383

24 U. von Wilamowitz-Moellendorf, «Unechte Briefe», Hermes 33, 1898, pp. 492-498, aquí 492-494.

25 Jenofonte, Cinegético, 4.1.

26 F.Blass, «Unechte Briefe», RhM 54, 1899, pp. 33-39, aquí pp. 34-35.

27 Philippe..., ob. cit., (nota 4), pp. 43-46. Los argumentos están recogidos en parte en 
thieu fueron luego aceptadas por La Rue van Hook, el editor de Loeb ${ }^{28}$.

Desde entonces nadie ha dudado de la autenticidad de la carta, a pesar de que todavía quedaban algunas «questions embarrassantes» según concedía el propio Mathieu. En realidad pocos parecen haber leído con detalle los argumentos de Keil, que no se limitaban simplemente al valor de las palabras $\ddot{\alpha} \tau \tau \alpha$

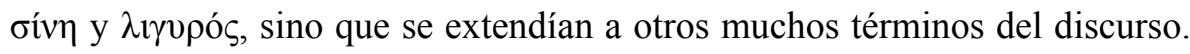
Es más, como vimos, Keil consideraba lo inapropiado de ciertas comparaciones rebuscadas en el interior de la carta así como la torpeza de algunas construcciones. Todo ello hacía imposible pensar en una carta privada o confidencial, pues, como el propio Keil subrayaba, este tipo de cartas suelen ser mucho más breves y carentes de todo adorno literario. Como sabemos por el repertorio de cartas de recomendación recopilado por Chan-Hie Kim ${ }^{29}$, éstas suelen ser breves misivas que van directamente al asunto que concierne. $\mathrm{Su}$ brevedad se explica tal vez simplemente porque es la persona que escribe la carta la que supone la mayor recomendación. Una elaboración prolija y literaria como la que tiene lugar en la carta de Isócrates se entiende únicamente porque la carta va dirigida a un gran público y no sólo al destinatario.

Esto sólo bastaría para invalidar la tesis de Blass y Mathieu, pero es que además no se ha tenido en cuenta tampoco que las cartas VII y VIII son también cartas de recomendación y carecen de todos los problemas estilísticos señalados para la carta IV. Que las tres cartas pertenecen al género de cartas de recomendación se puede observar por la presencia en ellas de una serie de fórmulas similares. Así, en la carta IV Isócrates dice a su interlocutor en $\S 13$ que no se asombre porque la carta que le ha escrito sea tan extensa ( $\mu \grave{\eta} \theta \alpha v \mu \alpha ́ \sigma \eta n s$,

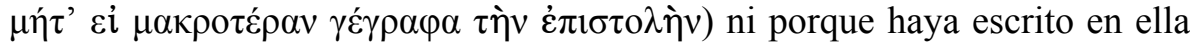

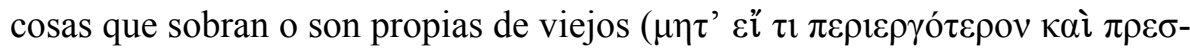

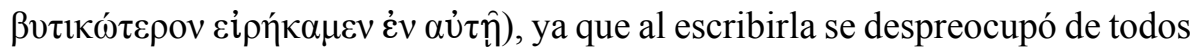

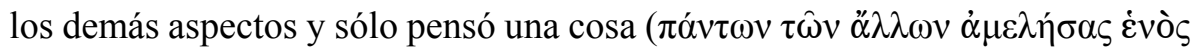

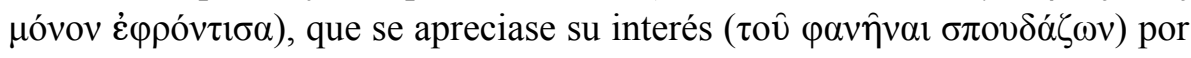
amigos suyos que se habían convertido en personas muy queridas para él.

Esta preocupación por hacer público su interés por los amigos la encontramos también en la carta VII, donde en $§ 10-11$ Isócrates pide a Timoteo que

Mathieu, Isocrate, ob. cit., vol. IV, pp.178-179.

28 Isocrates III, ed. L. van Hook, Cambridge 1945, p. 411.

29 C.-H. Kim, Form and Structure of the familiar Greek letter of recommendation, Missoula (Montana), 1972. 
emplee a su servicio a Autócrator, el portador de la carta, que es íntimo su$\mathrm{yo}^{30}$. En efecto, Isócrates dice allí que quiso que Autócrator fuese bien acogido por Timoteo y de manera satisfactoria para ambos para que así fuese evidente que Autócrator obtenía aquello que necesitaba gracias a su intercesión

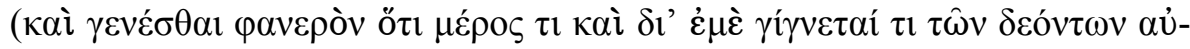
$\tau \hat{\omega})$. Sigue diciendo Isócrates a su destinatario que no debe asombrase de que

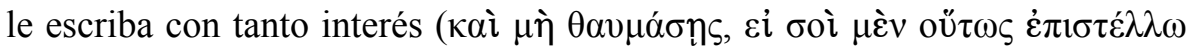
$\pi \rho \circ \theta v ́ \mu \omega \varsigma)$, aunque nunca pidió nada a su padre Clearco, pero que ello se

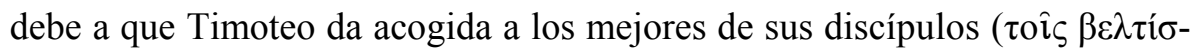

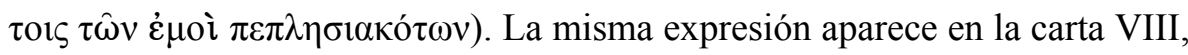
que es toda ella una carta de recomendación de los hijos de Afareo ante los gobernantes de Mitilene. En la conclusión de la carta escribe Isócrates que sus destinatarios no deben asombrarse de que haya escrito la carta con más in-

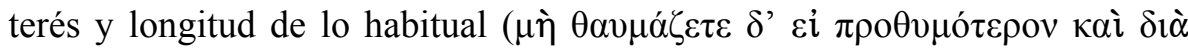

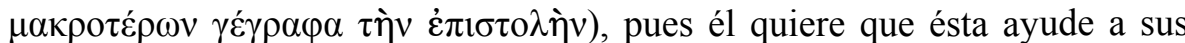

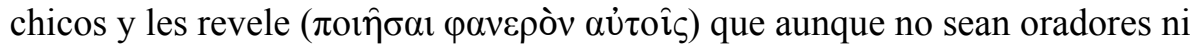

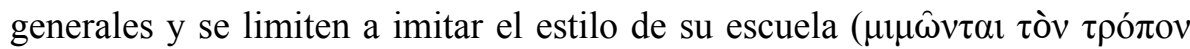

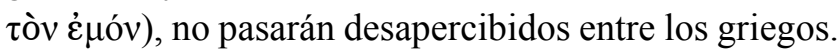

La fórmula es tan idéntica en las tres cartas ${ }^{31} \mathrm{y}$ el énfasis en su divulgación tan claro en todas ellas, que la única interpretación posible es que estas cartas de recomendación, además de servir para recomendar a una persona en concreto, servían igualmente para divulgar la fidelidad y el apoyo que daba Isócrates a sus discípulos. Esto no sólo beneficiaba a Isócrates como persona, sino, y en ello creo que está la clave de esta insistencia en la divulgación, a la propia escuela que él dirigía. Se trataba en estas cartas de demostrar que el maestro no dejaba nunca de ayudar a sus discípulos y allegados, lo que daba prestigio a su propia actividad. De ahí la insistencia en la divulgación y de ahí quizás la razón de que estas cartas se hayan conservado entre el conjunto de cartas atribuidas a Isócrates: no se trataba de simples cartas de recomendación, sino de cartas de recomendación reelaboradas literariamente para dar

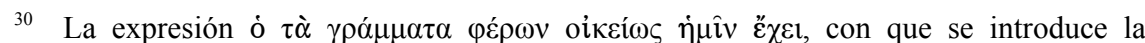
sección de la carta VII que tiene que ver estrictamente con la recomendación, es, según vemos por el repertorio de Kim, ob. cit., pp. 37-53, la típica fórmula de identificación del recomendado en las cartas de recomendación.

31 Véase en las tres el giro $\mu \grave{\eta} \theta \alpha v \mu \alpha ́ \sigma \eta n \varsigma$, la indicación a la publicidad con las formas

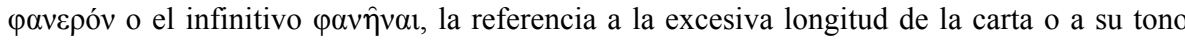
quizás demasiado vehemente etc. 
publicidad a la escuela de Isócrates. Prueba de que formaban una unidad puede estar en el hecho de que las tres cartas, a pesar de estar escritas en fechas muy diversas, aparecen copiadas juntas al final de la colección nada menos que en cinco manuscritos ${ }^{32}$.

Una vez demostrado que la carta IV no puede diferenciarse de las cartas VII y VIII por su condición de carta de recomendación, queda sin embargo explicar por qué sólo el estilo de esta carta IV dirigida a Antípatro está tan en contradicción con el de Isócrates. Frente a la suposición de Wilamowitz, pienso que no hay que pensar en una falsificación realizada por Diodoto o su hijo a la muerte de Isócrates: como bien han indicado muchos estudiosos posteriores no se ve razón alguna para esa falsificación. Pero esto no significa tampoco necesariamente que fuese Isócrates el autor mismo de la carta. La formalización con que se escriben estas cartas permite pensar que Isócrates pudiese confiar ocasionalmente su redacción a alguno de los propios recomendados, ya que éstos eran al fin de cuentas miembros de su escuela y por lo tanto conocedores de los mecanismos y recursos que determinaban este tipo de composiciones. Esto es lo que pudo ocurrir con la carta IV a Antípatro y para ello me apoyo precisamente en la fecha en la que se supone fue escrita: probablemente en el año 340, si hacemos caso a la indicación de que Atenas estaba entonces en guerra con Macedonia. Ahora bien, como hemos visto en el análisis del Panatenaico, Isócrates estuvo enfermo entre el año 342 y el 339 , de forma que tuvo que interrumpir precisamente durante estos tres años la redacción del discurso. ¿No es posible pensar que justamente durante ese periodo en el que nuestro orador se vio imposibilitado para escribir, delegara a veces en sus discípulos la redacción de escritos de circunstancias como es la presente carta a Antípatro? Ello explicaría no sólo el torpe estilo de la carta y la inconveniencia de alguna de sus afirmaciones, sino el hecho sorprendente de que la carta carezca de cualquier alusión a la persona o figura de Antípatro, frente a lo que ocurre en las otras cartas, en las que la recomendación en sí ocupa incluso menos espacio que la amplia captatio beneuolentiae dirigida al destinatario. Si Diodoto escribió la carta ¿cómo iba a poder decir algo sobre Antípatro, al que él mismo no había tratado? De acuerdo con esta idea, Diodoto no incluyó nada referente a la persona del macedonio, pero se extendió en las circunstancias de su vida y las de su hijo, que refiere en estilo

32 Vat. gr. 64, Vat. gr. 1461, Palatinus 134, Helmstad. 806 y Laur. LXX.19. 
indirecto poniéndolas en boca de Isócrates ${ }^{33}$.

Tampoco hay que descartar sin embargo que redactase la carta un colaborador estrecho de Isócrates, como su propio hijo Afareo, del que sabemos por la Vida de Isócrates 839 del Pseudo-Plutarco que escribió diversos discursos y obras trágicas y estuvo sin duda muy cercano a su padre al que erigió estatuas y que, como veremos en el apartado 4.2, fue además un estrecho colaborador suyo. Obviamente Isócrates tuvo que dar el visto bueno a la carta

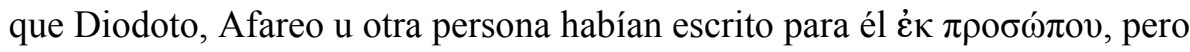
quizás su intervención se limitó a la introducción y al cierre y a limar alguno de los fallos más evidentes.

Queda por lo tanto únicamente explicar cómo es posible que Isócrates pudiera permitir que se hiciera pública una carta suya al macedonio Antípatro en tiempo de guerra entre Atenas y Macedonia. La cuestión llevó incluso a Münscher a considerar que la carta no era auténtica, pues no era posible esperar una correspondencia semejante en guerra ${ }^{34}$. No obstante, no hay nada que en la carta aluda a la situación política. Aunque el hecho de que Isócrates recomendase a un discípulo suyo ante Antípatro podría hacerlo sospechoso ante los sectores radicales atenienses, hay que tener en cuenta que estas cartas no tenían otro objetivo, como hemos visto, que demostrar la fidelidad del maestro hacia sus discípulos. La insistencia en este particular es en la carta IV mucho mayor que en las otras dos, ya que en $§ 13$ Isócrates señala que ésta es la única consideración que le movió con exclusión de todas las demás ( $\pi \alpha \dot{v} v \tau \omega v$ $\tau \hat{\omega} v \ddot{\alpha} \lambda \lambda \omega v \dot{\alpha} \mu \varepsilon \lambda \eta \dot{\eta} \sigma \alpha \varsigma \dot{\varepsilon} v o ̀ \varsigma \mu o ́ v o v \dot{\varepsilon} \varphi \rho o ́ v \tau \imath \sigma \alpha)$. El carácter público que necesariamente debía tener la carta por sus pretensiones literarias nos hace suponer que Isócrates corría obviamente riesgos al permitir que se redactase ese escrito recomendando a un discípulo ante un potentado macedonio. Son esos los riesgos a los que alude precisamente al comienzo de la carta. Pero el viejo orador, fiel a sus convicciones, no dejó incluso de favorecer a sus amigos en tiempos de guerra, al margen de sus propias ideas políticas. Quizás esta circunstancia explica también que no haya referencia alguna a la persona del destinatario.

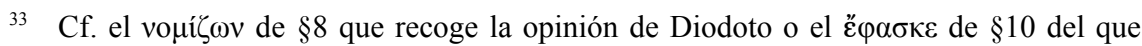
dependen una serie de sintagmas en infinitivo que recogen sus propias palabras.

$34 R E$ s.v. «Isokrates», col. 2217. 


\section{La carta a Alejandro (V)}

La carta V, dirigida a Alejandro Magno, es la más corta de todas las atribuidas a nuestro orador. Isócrates la envía a Alejandro junto a otra que dirige a su padre para que, según declara al principio de ella, los lectores no lo consideren un necio debido a su gran edad y se den cuenta de que todavía le queda algo del raciocinio que tenía cuando era joven $(\$ 1)$. Cuenta Isócrates a

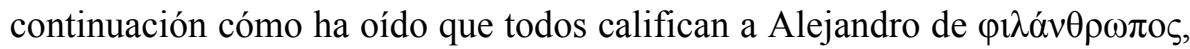

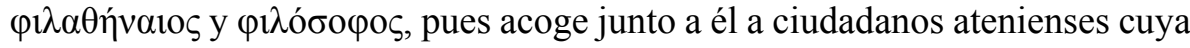
compañía puede resultarle muy provechosa ( $(2)$. Sabe nuestro orador que

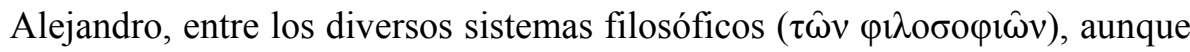

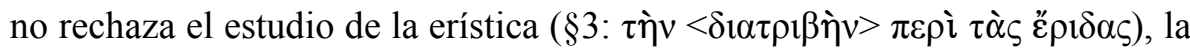
considera quizás útil en asuntos privados, pero inapropiada para los gobernantes o monarcas que no deben caer en semejante tipo de debates. De ahí que Alejandro se haya entregado al estudio de la retórica (§4: $\tau \grave{\eta} \nu$

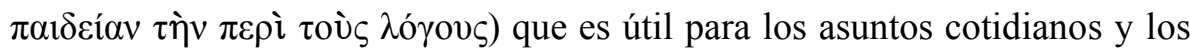
problemas públicos. Gracias a ella Alejandro podrá, continúa Isócrates, hacer predicciones razonables sobre lo que puede ocurrir, dar órdenes adecuadas a

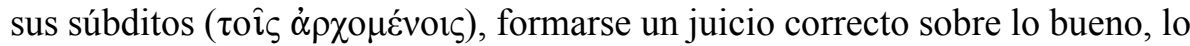
justo y sus contrarios así como juzgar y castigar a cada cual según lo que debe (§4). Si sigue así podrá superar a los demás del mismo modo que su padre Filipo ha superado a todos ( $\$ 5)$.

Para todos los autores que han analizado la carta, el interés de Isócrates por la educación de Alejandro sólo puede entenderse a partir de la llegada de Aristóteles a la corte macedonia como su preceptor: la enseñanza filosófica de contenido erístico que descalifica el escrito sería justamente la impuesta por Aristóteles al joven príncipe. Dado que la llegada del estagirita a Macedonia se produjo en el arcontado de Pythodotos, es decir entre julio del 343 y julio del $342^{35}$, la carta debía ser posterior a esta fecha. Es más, la carta habría tenido que ser enviada cuando Alejandro y Filipo se hallasen juntos, tal como se indica en el párrafo inicial, lo que según Wilamowitz sólo podía ocurrir durante el invierno ${ }^{36}$. El autor propuso así como fecha los meses iniciales de los años 341 o 340, pues en octubre del 340 estallaba la guerra entre Atenas y Macedonia. Enseguida consideraremos con más detalle las

35 Nuestras fuentes son Dióg. Laercio V.10 y Dion. de Halicarnaso, I A Ameo 5.3.

36 Wilamowitz, Aris. und Athen ..., ob. cit., p. 398. 
implicaciones de estas fechas. Basta ahora por el momento con señalar que en los años 342-341 Alejandro contaba 14-15 años, ya que había nacido en el verano del 356.

Pero no es la fecha de la carta lo que más ha preocupado a los estudiosos, sino el hecho de que Isócrates señale en ella que Alejandro comparte con él su escaso interés por la erística y su afición por la retórica. Ya Wilamowitz llamó la atención sobre la poca credibilidad que le merecía el hecho de que Alejandro, tal como Isócrates indica en la carta, se sintiese atraído por la enseñanza de la retórica:

Von der Rhetorik hat der größe König nachmals wenig genug gehalten, weder selbst die isokrateische Kunst geübt, noch neben Hofpoeten, Hofphilosophen und Hofkünstlern aller Art Hofrhetoren angestellt, es sei denn man rechne die historiographen Anaximenes und Kallisthenes mit, die Isokrates nicht anerkannt haben würde. Die einfachen Glockentöne Homers, nicht die künstlichen Fugen und Passagen des Panegyrikos haben seine Heldenseele zum Zuge gegen die Barbaren begeistert. Also muß Isokrates schlecht berichtet gewesen sein, oder vielmehr, er war es wohl gut, und gerade deshalb schrieb er so wie er es getan hat, und weil er sich so anstellt, waren die Leser in der Lage, die Feinheit des Alten zu bewundern. Das ist weniger auf den Prinzen als auf den Hofmeister Aristoteles berechnet.

Para Wilamowitz resulta pues evidente que Alejandro no sintió el menor interés por la educación retórica de Isócrates, aunque esta constatación no resulta para él prueba de la falsedad de la carta, sino que justamente es el indicio más claro de su autenticidad. En efecto, según él, Isócrates convierte en realidad su deseo de que Alejandro estudie retórica y, basándose en lo que supuestamente ha oído, alaba al príncipe por aquello por lo que él querría que hiciese. Como Isócrates, prosigue Wilamowitz, no podía criticar directamente la enseñanza aristotélica, recurrió a esta crítica indirecta. De esta forma la carta no puede ser sino auténtica, ya que es más profunda de lo que pretende $\mathrm{y}$ alude de manera disimulada a hechos que son exactos.

Esta interpretación de Wilamowitz se convirtió enseguida en la communis opinio sobre la carta ${ }^{37}$. Basándose en su tesis, Philip Merlan realizó en 1955 el estudio más detallado de la carta hasta el momento ${ }^{38}$. Merlan partía también de la idea de que en la carta V Isócrates enunciaba sobre todo su propio

37 Münscher, RE s.v. «Isokrates», col. 2216; Mathieu, Philippe..., ob. cit., pp. 41-43; Mathieu, «Lettres», ob. cit., pp. 176-177.

$38 \mathrm{Ph}$. Merlan, «Isocrates, Aristotle and Alexander the Great», Historia 3, 1954-1955, pp. $60-81$. 
programa educativo y no las inclinaciones reales de Alejandro acerca de la educación que se le impartía: debido a la cortesía obligada en una composición dirigida al príncipe heredero de Macedonia, nuestro orador no podía criticar directamente el sistema de enseñanza erístico que Aristóteles estaba proporcionando a Alejandro y se veía obligado a desaprobarlo fingiendo hacerse eco de las supuestas preferencias del joven príncipe. En su estudio Merlan comparaba además la carta con pasajes paralelos de otras obras de Isócrates en los que también se vierten críticas a la educación erística y se defiende una educación práctica basada en la retórica (la "filosofía" de Isócrates): todos ellos revelaban las mismas preocupaciones e ideas por parte de nuestro orador. De esta forma quedaba confirmada la autenticidad de la carta, el único documento fiable con el que contamos para apreciar las bases de la educación de Alejandro. Sólo Jaeger ${ }^{39}$, refutado por Merlan ${ }^{40}$, cuestionó esta interpretación de Wilamowitz y defendió que la carta era espuria, pero sus argumentos se basaban sólo en la inverosimilitud de que Isócrates pudiera atreverse a refutar al preceptor de Alejandro.

La tesis de Wilamowitz, ampliada por Merlan, obligaba, como vimos, a fechar la carta con posterioridad al año 342 y antes del 340. Ello implica en primer lugar que se ha perdido la carta a Filipo a la que supuestamente acompañaba nuestro billete a Alejandro, ya que ninguna de las dos cartas a Filipo que se nos han conservado se escribieron en ese año o en una fecha próxima, algo que ya apuntó Meyer ${ }^{41}$ y que descalificaba lo que en su momento pensaron el propio Wilamowitz y otros autores ${ }^{42}$. No es en efecto posible adelantar o retrasar mucho la fecha de la carta $\mathrm{V}$ para hacerla coincidir con una de las dos cartas a Filipo y ello por varias razones. En primer lugar, si pensamos que la carta $\mathrm{V}$ pudo haberse escrito ya a principios del 344 y que fue enviada juntamente con la carta $\mathrm{II}^{43}$, nos encontramos con el problema de que

39 W. Jaeger, Demosthenes, Cambridge, 1938, pp. 253-254.

40 Merlan, «Isocrates...», ob. cit., p. 60 nota 3.

${ }^{41}$ Meyer, ob. cit. (nota 2), p. 109, nota 4.

42 Muchos estudiosos, partiendo de una falsa datación de la carta II que se refería a la herida de Filipo, pensaron que la V podía haber sido enviada junto con esta: así Wilamowitz, Aris. und Athen, ob. cit., p. 398, que dató las cartas II y V en 341 o 340; E. Drerup, Isocratis opera omnia, Leipzig, 1906, p. CLXI, en el invierno del 342/1; Hagen, ob. cit. (nota 2), p. 124, a comienzos del 343.

43 Sólo el Matr. 7210 y el Vat. gr. 1353, los dos manuscritos propiedad de Láscaris, presentan la carta V copiada a continuación de la II, acertando así con el orden correcto en 
su destinatario, Alejandro, apenas contaría con doce años por entonces, pues nació en el verano del 356. Aunque no habría problemas para pensar que un precoz Alejandro hubiera sido iniciado en la enseñanza retórica con esa $\operatorname{edad}^{44}$, parece excesivo atribuirle criterios y juicios tan maduros como los que pone Isócrates en su boca en esta carta ${ }^{45}$. Además, aunque sabemos que Alejandro contó con varios preceptores antes de la llegada de Aristóteles en el 343/342, tal como nos indica la biografía de Plutarco ${ }^{46}$, es probablemente a partir de ese momento cuando resulta quizás pertinente un debate de la erística frente a la retórica en los términos en los que lo plantea Isócrates. Por otro lado también, si queremos rebajar la datación de la carta, nos encontraremos con el problema de la inconveniencia de calificar de "amigo de Atenas" a Alejandro en el 341 o el 340, cuando el clima de enfrentamiento entre Atenas y Macedonia es total. Además Isócrates, no sólo estaba enfermo desde el 341, sino que antes de esa fecha había empezado a redactar el Panatenaico para defenderse de los ataques del partido antimacedonio. Por eso pienso que son demasiado tardías las fechas de comienzo del 341 o del 340 que se suelen dar para fechar la carta $\mathrm{V}^{47} \mathrm{o}$ incluso la de finales del 342 que sugieren Mathieu ${ }^{48}$ y van Hook ${ }^{49}$, y me inclino por pensar que la carta se envió quizás ya entre los años 343 y 342, coincidiendo por lo tanto con la llegada de Aristóteles. Son varios lo argumentos que me llevan a proponer esta fecha.

En primer lugar, parece descartado que Isócrates pudiera enviar a Alejandro una carta a finales del 342 o principios del 341 por la sencilla razón de que por aquellas fechas su padre Filipo estaba de campaña en Tracia. Se trató de una campaña excepcionalmente larga, que le retuvo durante más de diez meses, incluido el invierno, lejos de su patria, tal como sabemos por el discurso Sobre el Quersoneso de Demóstenes escrito en la primera mitad del

que debieron ser copiadas. Para ellos cf. infra nota 100.

44 En el año 340, con 16 años, Alejandro se hizo con responsabilidades de gobierno según sabemos por Plutarco, Vida de Alejandro 9.1-2.

45 Mathieu, Philippe..., ob. cit., pp. 41-42.

46 Plutarco, Vida de Alejandro, 5.7-8.

47 Mathieu, Philippe..., ob. cit., pp. 42-43

48 Mathieu, «Lettres», ob. cit., p. 177 se inclina por fechar la carta en el invierno del $342 / 341$ por ser esta la fecha más cercana al principio del preceptorado de Aristóteles (que era al fin de cuentas el detonante de la carta).

49 Van Hook, Isocrates III..., ob. cit., p. 425. 
$341^{50}$, según admiten hoy además la mayoría de los historiadores ${ }^{51}$. Está por lo tanto excluido que Filipo pudiera estar con su hijo Alejandro por esas fechas y que Isócrates pudiera dirigirse a ambos. No obstante, entre su intervención en Tesalia en el verano del 344 y su intervención en el Epiro en el verano del 342 para colocar en el trono de los molosos a su cuñado Alejandro ${ }^{52}$, no hay noticia de campaña alguna de Filipo que le mantuviera alejado de Macedonia. En cualquier momento entre ambas fechas el rey podría estar con su hijo Alejandro, aunque, como hemos dicho antes, la carta de Isócrates debe coincidir por lo menos con la llegada de Aristóteles a Macedonia, que tuvo lugar, como muy pronto en Julio del 343.

Otra consideración que me lleva a preferir esa temprana datación está basada en una indicación contenida en la carta que Espeusipo, sobrino de Platón y director de la Academia, envió a Filipo en el año 343 y en la que critica con dureza el discurso A Filipo. En esta carta Espeusipo declara enviar junto a Filipo a su alumno Antípatro de Magnesia con un discurso sobre la historia de Grecia mucho más favorable a las reivindicaciones territoriales de Filipo que las tesis ofrecidas por Isócrates en el discurso dedicado al rey. Minor Markle ha analizado brevemente el contenido de la carta y la grosera manipulación de la historia mítica operada por Espeusipo y Antípatro en beneficio de los intereses políticos del macedonio, pero sobre todo ha inscrito la redacción del escrito en el contexto de la polémica entre la Academia y la escuela de Isócrates por ganarse el favor del patrono macedonio ${ }^{53}$. En este sentido es interesante subrayar que la carta de Espeusipo, datable probablemente de la segunda mitad del año $343^{54}$, habla ya de la presencia en la corte macedonia de Teopompo, el famoso historiador y quizás el más conocido de los discípulos de Isócrates ${ }^{55}$. Según señala Espeusipo en su carta $(§ 12)$,

50 Dem. VIII.2 (Filipo lleva 11 meses en Tracia) y 35 (Filipo lleva 10 meses fuera y debido al invierno, la guerra y su enfermedad no ha podido regresar a casa:

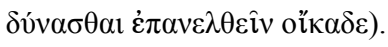

51 Hammond, Philip..., ob. cit., p. 122: Filipo ausente de Macedonia entre julio del 342 y abril del 341.

52 Cf. Hammond, Philip..., ob. cit., pp. 121-122.

53 Markle, ob. cit. (nota 16), pp. 92-99.

54 Markle, ob. cit., p. 92, nota 29.

55 Frente a quienes negaron la condición de maestro-discípulo que unía a Isócrates y Teopompo puede reenviarse simplemente al unánime testimonio de las fuentes antiguas que confirman esta relación (cf. R. Laquer en RE s.v. «Theopompos 9», cols. 2186-2192). Incluso M. A. Flower (Theopompus of Chios, Oxford, 1994), que pretende demostrar que el 
Teopompo no deja de calumniar a Platón ante el macedonio, algo que coincide con las informaciones que nos presentan a Teopompo como autor de escritos contra Platón ${ }^{56}$. Por esta razón Espeusipo insta a Filipo a que ordene que Antípatro lea ante presencia de Teopompo su obra histórica a fin de que éste

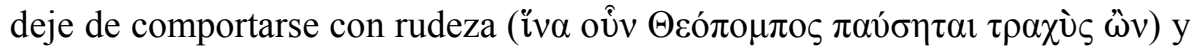
se dé cuenta de que todos tienen razón al despreciarlo mientras que Filipo le

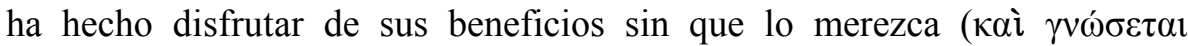

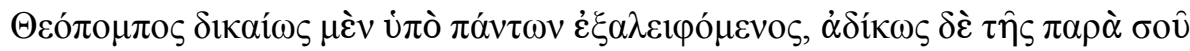

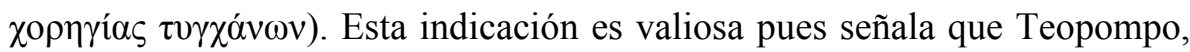
un discípulo de Isócrates, estaba ya asentado en la corte macedonia en el año 343 , pues estamos muy mal informados sobre los movimientos de la vida de Teopompo en general. Es evidente que esta indicación indica una cierta preeminencia de Teopompo en la corte de Filipo, que por estas fechas no se debería tanto a su condición de futuro historiador de las $\Phi ı \lambda \imath \pi \pi \imath k \alpha i$ i $\sigma \tau o \rho i ́ \alpha l$ que tomaron el reinado de Filipo como centro ${ }^{57}$, cuanto a la influencia de su maestro Isócrates en la corte macedonia a raíz de la publicación del A Filipo en el 346. Es para nosotros indiferente saber si Teompopo pudo haber sido llamado a Macedonia por Filipo simplemente como un intelectual de corte o con las miras puestas en la futura educación de Alejandro, en la que el rey pudo empezar a interesarse en ese largo periodo entre el otoño del 344 y el verano del $342^{58}$. Lo que nos interesa sólo es que las críticas de Espeusipo a Isócrates y a su discípulo Teopompo, revelan sin duda un influjo de estos dos últimos en la corte macedonia del 343, un inlfujo que los académicos estaban dispuestos a reemplazar mediante la obra de Antípatro de Magnesia. En este contexto cobra nueva relevancia tanto la carta $\mathrm{V}$ de Isócrates como la llegada de Aristóteles a Macedonia por esas mismas fechas.

La llegada de Aristóteles a Macedonia ha sido entendida como una victo-

historiador no fue discípulo del orador, no niega la «tremendous influence» de Isócrates sobre él (p. 62), lo que apunta a una relación entre ambos.

56 Cf. J. Geffcken, «Antiplatonika», Hermes 64, 1928-1929, pp. 87-109, esp. pp. 90-91.

57 Testimonios y fragmentos de su obra en FGrH 115.

58 No contamos con testimonios en la vida de Teopompo que permitan postular una relación con Alejandro en su juventud, pues las fuentes hablan sólo de contactos entre ambos cuando Alejandro era ya rey ( $R E$ s.v. «Theopompos 9», cols. 2219 ss.). Interesante es únicamente la indicación de Cicerón de que Aristóteles y Teopompo escribieron «quae ipsis honesta essent et grata Alexandro» (cartas a Ático XII.40.2), lo que podría apuntar a un papel común de ambos como educadores del príncipe. 
ria de la Academia frente a la escuela de Isócrates, pues aunque los motivos de la llegada de Aristóteles junto a Filipo no tengan que ver directamente con su vinculación a la Academia ${ }^{59}$, es evidente que su método era heredero del de Platón y que, como ha demostrado Merlán, no hay razones para suponer que tuviera por aquel entonces malas relaciones con Espeusipo ${ }^{60}$. El propio Merlan hizo ver claramente que la educación erística que ataca Isócrates en la carta $\mathrm{V}$ y en el resto de sus escritos no era tanto la practicada por Aristóteles como la seguida por los miembros de la Academia, verdaderos rivales de la escuela de Isócrates ${ }^{61}$. ¿Cabría pensar por lo tanto que la crítica a los métodos de enseñanza platónicos que realiza Isócrates en su carta $V$ no estuviera motivada tanto por el nombramiento concreto de Aristóteles como tutor de Alejandro, como por la rivalidad de Isócrates con la Academia en general? Son de hecho numerosos los estudios dedicados a la rivalidad entre Isócrates y la Academia de Platón y sus discípulos, que constituye un elemento clave para entender gran parte de la obra de nuestro orador ${ }^{62}$. Aunque el nombramiento de Aristóteles fuese el desencadenante de la carta V, nada habría de extraño en suponer que Isócrates la escribiese incluso un poco antes de la llegada de éste a Macedonia, en medio de la disputa existente entre académicos e isocráticos por el control de la educación de Alejandro. En este sentido la carta no habría supuesto una descalificación directa de Aristóteles después de que éste había sido confirmado en su puesto de preceptor del príncipe, precisamente el aspecto que más inverosímil resultaba a Jaeger y el que le movía

59 W. Jaeger, Aristoteles, Berlín, 1923, pp. 120-122 postuló por primera vez que Aristóteles fue llamado por Filipo porque Hermias (el tirano-filósofo de Atarneo y discípulo de Platón en cuya corte se hospedaba Aristóteles) había pactado con Filipo II una alianza frente al persa (cf. W.K.C. Guthrie, Historia de la filosofía griega, vol. VI: Introducción a Aristóteles, Madrid, 1993 [trad. de la ed. Cambridge, 1981], pp. 48-50 y S. Hornblower en Cambridge An. Hist., ob. cit., pp. 94-95). Otros autores consideran que Aristóteles fue llamado porque su padre Nicómaco fue el médico del padre de Filipo II (para fuentes sobre la familia y biografía de Aristóteles cf. I. Düring, Aristotle in the ancient biographical tradition, Göteborg, 1957).

${ }^{60}$ Ph. Merlan, «Zur Biographie des Speusippos», Philologus 103, 1959, pp. 198-214, esp. pp. 206-210.

${ }_{61}$ Merlan, «Isocrates...», ob. cit.

${ }^{6}$ Cf. Ch. Eucken, «Leitende Gedanken im isokratischen Panathenaikos», MH 39, 1982, pp. 43-70 para las constantes referencias a los platónicos en el último discurso de Isócrates, contemporáneo a la presencia de Aristóteles en Macedonia. Pionero en este campo fue el estudio de H. Gomperz, «Isokrates und die Sokratik», Wiener Studien 27, 1905, pp. 163-207 y 28,1906, pp. $1-42$. 
a considerarla falsa. La carta habría podido ser escrita justamente para prevenir la posible influencia de los académicos ante Filipo y haber sido escrita ya a finales del 343, por las mismas fechas en las que Espeusipo enviaba su misiva a Filipo. El hecho de que ni Isócrates mencione los argumentos de Espeusipo contra él en su carta a Alejandro, ni Espeusipo mencione en ningún momento a Alejandro en su misiva, permite pensar que hubo más cartas de ambos a la corte macedonia. En el caso de Isócrates tenemos la referencia en la carta $\mathrm{V}$ a la perdida carta a Filipo a la que acompañaba. En el caso de Espeusipo, el tono inmediato y directo de la misiva parece implicar una correspondencia anterior.

Pienso además que no sólo la carta V sino también el propio Panatenaico, que Isócrates empezó a escribir en el año 342, pueden inscribirse dentro de esta polémica con los académicos, pues en este discurso nuestro orador parece responder a algunos de los argumentos planteados por el platónico. En efecto, en su misiva Espeusipo no sólo critica duramente a Teopompo, sino que acusa a Isócrates de vender el mismo discurso a todo tipo de gobernantes (§13) y, sobre todo, dice que Isócrates no ha sido capaz de legitimar ciertas ambiciones territoriales de Filipo sobre Atenas con argumentos de la historia. Éste es el motivo principal de la carta de Espeusipo, ya que el escrito que Antípatro lleva al rey con ella trata precisamente de estas cuestiones y justifica con frecuentes apelaciones a las acciones de Heracles, supuesto ancestro de Filipo, las legítimas aspiraciones de éste sobre ciertos territorios en contra de los intereses de Atenas ${ }^{63}$. Isócrates no podía dejar sin respuesta semejantes graves acusaciones, con las que la Academia demostraba además su poco patriotismo al vender argumentos a Filipo contra Atenas. Si la carta V no menciona estas críticas, sí tal vez el Panatenaico, donde Isócrates empieza justamente haciendo una defensa de su patriotismo como ateniense y rechazando los relatos míticos ${ }^{64}$. Su reivindicación de la antigua Atenas es, como vimos, el objeto principal del discurso y estaba motivada por los ataques que contra él dirigieron sectores antimacedonios descontentos con su A Filipo. Sin embargo en la obra, Isócrates no sólo critica a los oradores demagogos, sino que además pretende poner fin a las calumnias a las que le someten "sofistas perversos e indignos" (Panatenaico 5-6). Muchos estudiosos han visto

63 Para los argumentos de la historia mítica sacados a colación por Espeusipo para defender las ambiciones territoriales del macedonio cf. Markle, ob. cit., pp. 94-96

${ }_{64}$ Como $\mu \hat{\theta} \theta 01$ califica precisamente Espeusipo sus argumentos sacados de la historia. 
justamente en la alusión de Panatenaico 33 a los sofistas del Liceo una referencia a miembros de la Academia ${ }^{65}$. Es evidente que Isócrates, criticado por su postura promacedonia por sectores políticos próximos a Demóstenes y desacreditado además ante Filipo por miembros de escuelas rivales, tenía razones para considerar amenazado su prestigio entre sus conciudadanos (Panatenaico 5-6). Su respuesta consistió en refutar a todos haciendo una reivindicación del pasado ateniense que en primer lugar dejara a salvo su patriotismo frente a los ataques de los demosténicos, pero que además sirviera para descalificar a los académicos por su interpretación interesada de ese mismo pasado de su ciudad. En consecuencia: el Panatenaico, iniciado justamente en el año 342, podría haber servido también como respuesta a la carta de Espeusipo. Pero si esto no bastara para pensar que la carta V y el Panatenaico se redactaron en momentos muy próximos, puede señalarse también el hecho de que en el comienzo de la carta V Isócrates diga que escribe esta misiva para que sus enemigos no piensen que "está fuera de sus cabales debido a la edad y que no hace sino decir absolutas necedades" ( $\mu \grave{\eta} \ldots \mu \varepsilon$

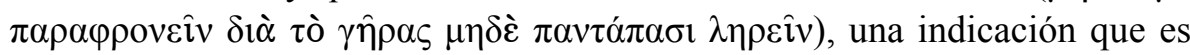
muy similar a la que hace en el Panatenaico 23 donde señala que sus enemigos no dejarán de acusarle de no dejar de decir necedades debido a su gran

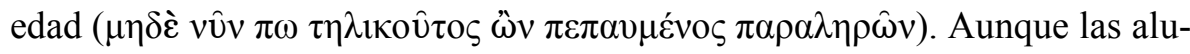
siones a la edad son frecuentes en las últimas obras de Isócrates, no se puede negar que éstas adquieren una dimensión especial al principio del Panatenaico con respecto a otras obras de nuestro orador.

Finalmente, hay que tener en cuenta que la carta $\mathrm{V}$ de Isócrates, como toda carta pública, no se dirigía sólo al rey sino al público ateniense en general y a los rivales de la Academia en particular. De hecho Isócrates se refiere a los lectores como uno de los motivos que le llevan a escribirla: Isócrates cree que sería improcedente escribir sólo a Filipo sin enviar unas letras al hijo que

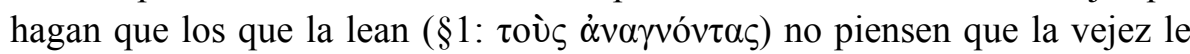
hace ya decir necedades. Es decir: parece ser que son sus lectores, conocedores de sus cartas y de su discurso A Filipo, los que le exigen un escrito a Alejandro y que esta obra responde básicamente a su petición. Esta carta pudo haber surgido pues de las necesidades de defender su escuela y sus

65 En el Liceo se reunían tal vez por aquellos años sofistas próximos a la Academia: Merlan, «Isocrates...», ob. cit.., p. 69 nota 2, sugiere que es en esos sectores donde encontraría posteriormente su apoyo Aristóteles al fundar el Perípato. 
postulados frente a los académicos y encaja perfectamente en el ambiente de los meses finales del 343 o principios del 342 en los que Espeusipo escribió su carta. No sabemos cuál fue la influencia real de Teopompo y de la escuela de Isócrates después de esa fecha y con la llegada de Aristóteles, pero pienso que es exagerado afirmar, tal como hacía Wilamowitz, que esa influencia nunca existió. Es pues probable que las ideas y enseñanzas de Isócrates tuvieran algún eco en la corte macedonia ${ }^{66}$, aunque el influjo que supuestamente ejercieron sobre Alejandro haya sido a veces exagerado ${ }^{67}$.

\section{La segunda carta a Filipo (III).}

\subsection{Contenido de la carta y estado de la cuestión}

Isócrates comienza la carta III dirigida a Filipo diciendo que ya ha discutido con Antípatro detalladamente las medidas que cree serán beneficiosas tanto para Atenas como para el rey y que ahora ha decidido escribir al rey pa-

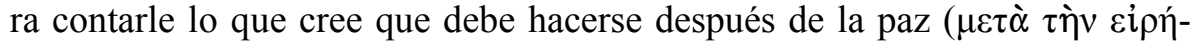
vๆv), aunque lo hará de manera mucho más breve a como lo hizo en su discurso (se entiende: el A Filipo del 346). En el momento de redacción del discurso, sigue diciendo Isócrates en $\S 2$, era preciso convencer a los atenienses para que se reconciliaran con Esparta, Tebas y Argos, pero ahora debido

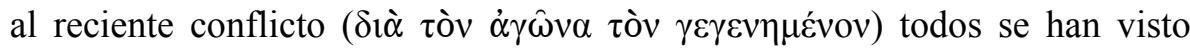
obligados a actuar sensatemente. Finalizadas las rencillas entre los griegos es de esperar que ahora emprendan la guerra contra Asia. Muchos preguntan a Isócrates si la idea de esta guerra fue suya o de Filipo, pero el orador no es capaz de dar una respuesta clara, pues sólo recientemente ha entablado relación con Filipo ( 33$)$. Isócrates se disculpa a continuación por dirigirse a Filipo por carta, ya que la edad no le permite presentarse ante él (§4) y le insta a emprender la noble empresa de la guerra contra el bárbaro, que le proporcionará una gloria que ninguna otra acción será capaz de aumentar (§45). Concluye la carta Isócrates dando gracias a que su edad le haya permitido ver cómo se va a cumplir la empresa con la que soñó en su juventud y que defendió en el Panegírico y en el discurso que envió al rey (\$6).

La datación de la carta en el 338 ha sido defendida casi unánimente por to-

66 Markle, ob. cit., pp. 89-92.

67 Hagen, ob. cit. 
dos los estudiosos ${ }^{68}$, pues se consideró que el conflicto ( $\left.\dot{\alpha} \gamma \hat{\omega} v \alpha\right)$ al que Isócrates se refería en $\$ 2$ no podía ser sino el de la batalla de Queronea de ese año, en la que Filipo derrotó a tebanos y atenienses. Sólo esta circunstancia, se creía, podía explicar que Isócrates pudiera pensar que ya no había obstáculo alguno a los proyectos del rey macedonio de emprender una campaña contra el persa, campaña que hasta entonces no había sido posible por el enfrentamiento con Atenas. Sin embargo esta datación de la carta III planteaba dos serios problemas de interpretación: 1) ¿cómo se compagina una felicitación de Isócrates al rey Filipo en el 338 con el hecho de que la tradición biográfica posterior nos diga que Isócrates, conmocionado por las noticias de la batalla de Queronea, se dejó morir de hambre?; 2) ¿es posible que Isócrates pudiera felicitar tan efusivamente a Filipo cuando su propia patria, Atenas, acababa de ser derrotada en batalla por sus tropas?

La respuesta a estos dos interrogantes se resolvió en la investigación posterior en dos posturas claramente enfrentadas. Unos autores defendieron la autenticidad de la carta por encima de cualquier otra consideración y, partiendo de su datación en el 338, intentaron descalificar como válidas las noticias de la tradición biográfica griega acerca del suicidio de Isócrates después de Queronea. Para estos autores estas noticias sobre el "patriótico" suicidio de Isócrates habrían sido difundidas por personas próximas al orador para defender su prestigio y su memoria ante los atenienses, que no podían ver con buenos ojos su posición promacedonia. Pequeñas contradicciones de la tradición biográfica les servían como punto de partida de su hipótesis ${ }^{69}$. Otros autores por el contrario consideraron inconcebible que Isócrates hubiera podido escribir la carta III a Filipo en el 338 después de la derrota de su ciudad en Queronea, por lo que la consideraron una falsificación de la cancillería macedonia y encontraron la principal prueba de su hipótesis en la unanimidad

\footnotetext{
68 Salvo por Ph. Wagner, Adnotationes criticae in Isocratis epistolas, en Programm des Marien-Gymnasiums zu Jever, 1875, y por Koepp, «Isokrates als Politiker», Preussische Jahrbücher 70, 1892, pp. 486-487. Sobre su propuesta volveremos en 4.4.

69 F. Blass, «Isokrates' dritter Brief und die gewöhnliche Erzählung von seinem Tode», RhM 20, 1865, pp. 109-116, Die attische Beredsamkeit..., ob. cit., vol. II, pp. 96-100 у 328 у «Unechte Briefe», ob. cit. (nota 26), pp. 33-39; Hagen, ob. cit. (nota 2); P. Wendland, «Beiträge zu athenischer Politik und Publicistik des vierten Jahrhunderts. I. König Philippos und Isokrates», en Nachrichten von der Königlichen Gesellschaft der Wissenschaften zu Göttingen. Philol.-hist. Klasse, Berlín 1910, pp. 123-182, aquí 177-182; J. Mesk, «Der dritte Brief des Isokrates», Wiener Studien 38, 1916, pp. 20-34; Mathieu, Philippe..., pp. 46-50 у «Lettres», ob. cit., pp. 180-183.
} 
de la tradición biográfica antigua que atestiguaba el suicidio de Isócrates después de la batalla ${ }^{70}$. Entre estas dos posturas excluyentes, la crítica se inclina hoy mayoritariamente a favor de la autenticidad de la carta, lo que ha supuesto que hasta ahora no se haya dado crédito al relato de la tradición biográfica sobre el suicidio de Isócrates después de Queronea.

Desde entonces los nuevos estudios no han hecho sino repetir los argumentos de la bibliografía más antigua. En realidad pienso que la cuestión se ha cerrado en falso y que no es posible: 1) ni descalificar sin más las informaciones de la tradición biográfica antigua, 2) ni postular tampoco la falsedad de la carta. Para demostrar ambos puntos vamos a someterlos primero a un análisis por separado en el que prescindiremos en principio de consideraciones que determinen la interpretación de la carta III a partir de la tradición biográfica o viceversa. Una vez demostrado que la carta es auténtica y que también lo es la tradición que postula que Isócrates se dejó morir de hambre en el 338 tras la batalla de Queronea, adelantaremos una hipótesis (iya propuesta en 1875!) que conjuga perfectamente ambos hechos y encaja además con la interpretación que hicimos del Panatenaico en la segunda entrega de este estudio.

\subsection{La muerte de Isócrates en el 338}

Son varias las fuentes griegas que nos transmiten noticias sobre la muerte de Isócrates. La más antigua de todas es probablemente la vida de Isócrates pergeñada por Dionisio de Halicarnaso al comienzo de su estudio dedicado a nuestro orador, escrito a finales del siglo I a. C. ${ }^{71}$. Dionisio describe la muerte de Isócrates en estos términos:

$A$. Murió en el arcontado de Queronides, pocos días después de la batalla de Queronea, habiendo vivido cien años a falta de dos, pues decidió poner fin a su vida junto con los

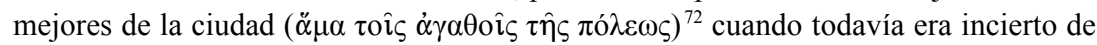

70 Wilamowitz, Aris. und Athen, ob. cit., vol. II, pp. 395-397 у «Unechte Briefe», ob. cit. (nota 24), pp. 494-496; K. Münscher, reseña de P. Wenland, Beiträge..., en Berliner Philologische Wochenschrift 28 Oct. 1911, cols. 1343-1352 y RE s.v. «Isokrates», cols. 22192220; P. Treves, «Tre interpretazioni Isocratee», Reale Istituto lombardo di scienze e lettere. Randiconti, 66, 1933, pp. 303-319, aquí 308-313 («La terza lettera»).

71 Dionisio de Halicarnaso, Oradores áticos III 1.

72 En la edición de G. Aujac (París 1978) esta autora traduce la expresión como «l'effondrement de la cité», por entender que el autor se refiere a $\tau \dot{\alpha} \dot{\alpha} \gamma \alpha \theta \grave{\alpha} \tau \hat{\eta} \varsigma \pi$ $\operatorname{\lambda }_{\varepsilon \omega \varsigma}$ (idén-

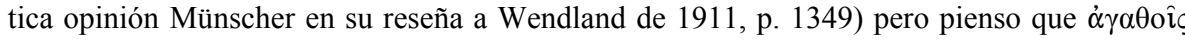
debe referirse más bien (en masculino y no en neutro) a los "nobles" atenienses muertos en la 
qué modo utilizaría Filipo su éxito una vez convertido en dueño de Grecia.

Según esta noticia Isócrates habría muerto en los instantes posteriores a la batalla de Queronea, cuando en la ciudad, tal como sabemos perfectamente por el discurso Contra Leócrates de Licurgo, estalló el pánico y se pensaba que las tropas macedonias iban a tomarla al asalto. La indicación de 98 años y la del arcontado de Queronides encajan perfectamente en el año 338.

En Pausanias I 18.8, que escribe en la segunda mitad del siglo II, encontramos también una pequeña nota sobre la muerte de Isócrates motivada por la mención de una estatua del orador:

$B$. Hay sobre una columna una estatua de Isócrates, que dejó tres cosas para el recuerdo: su gran entrega al trabajo, porque nunca dejó de tener discípulos aunque llegó a vivir cien años a falta de dos; su gran prudencia, porque vivió al margen de las responsabilidades políticas y sin intervenir en los asuntos públicos; su sentido de la libertad, porque ante la noticia de la batalla de Queronea se dejó morir voluntariamente

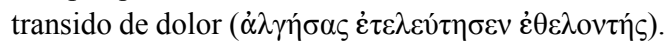

La siguiente noticia la encontramos en Macrobioi 23. En esta obra, dedicada a personajes longevos de la Antigüedad y transmitida dentro del corpus de Luciano de Samosata, leemos a propósito de Isócrates:

$C$. Isócrates escribió el Panegírico cuando cumplió noventa y seis años y cuando le faltaba un año para cumplir cien, al enterarse de que los atenienses habían sido derrotados por Filipo en la batalla de Queronea, lanzando grandes lamentos, recitó este verso de Eurípides aplicándoselo a sí mismo: «Cadmo, que dejó otrora la villa de Sidón» y, añadiendo que esclavizaría a Grecia, abandonó esta vida.

No hay más variación con respecto a noticias anteriores que la indicación de 99 años, cuya divergencia de la cifra de 98 es fácilmente explicable por un cálculo inclusivo. Sí es nueva la indicación de que Isócrates recitó un verso de Eurípides antes de morir que aludía a la esclavitud de Grecia en manos de un nuevo bárbaro como el fenicio Cadmo.

De fecha próxima pueden ser dos noticias que aparecen recogidas en la Vida de Isócrates incluida en las Vidas de los diez oradores áticos 837E-F y 838B, una obra conservada entre los escritos de Plutarco que contiene numerosas noticias sobre el orador y su familia:

D.1. Murió en el arcontado de Querondas, cuando, al enterarse de las noticias que llegaban sobre Queronea mientras estaba en la palestra de Hipócrates, se quitó la vida en cuatro días privándose de comida después de pronunciar el comienzo de tres

batalla de Queronea. Este aspecto tendrá su relevancia, como enseguida veremos. 
dramas de Eurípides: «Dánao, el padre de cincuenta hijas», «Pélope, hijo de Tántalo, al llegar a Pisa», «Cadmo, que dejó otrora la villa de Sidón». Vivió noventa y ocho años, o, según algunos, cien, al no soportar ver a Grecia esclavizada por cuarta vez. $[\ldots]$

D.2. Dejó de vivir, según dicen unos al noveno día por privarse de comida, según otros al cuarto juntamente con las ceremonias fúnebres de los caídos en Queronea ( $\alpha$ $\mu \alpha \tau \alpha \hat{\imath} \varsigma$

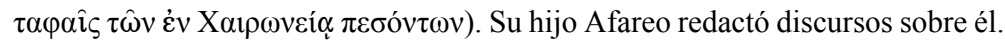

Frente a versiones anteriores, la primera noticia (D.1) del Ps.Plutarco indica que Isócrates daba su clase en la palestra de Hipócrates y cita dos versos más de Eurípides que Isócrates habría pronunciado al morir. La divergencia entre la indicación de que el orador murió a los 98 o a los 100 años es fácil de comprender si se considera que muchos autores redondean en 100 la cifra de los años de nuestro orador (véase infra noticia E) y que además otros autores, como Dionisio de Halicarnaso indican su edad con expresiones como "cien años a falta de dos". En cualquier caso D.1 indica que el autor de esta noticia manejaba más de una fuente. La segunda noticia (D.2) señala que el orador se murió después de nueve o cuatro días ${ }^{73}$ de abstinencia de todo alimento en el momento en que se celebraban los funerales por las víctimas de Queronea. Sabemos que estos funerales tuvieron lugar meses después de la batalla, pro-

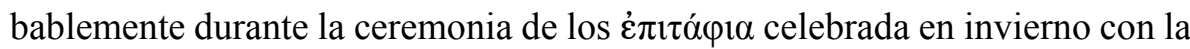
que Atenas honraba a sus héroes ${ }^{74}$. La noticia, interpretada literalmente, hace pensar que Isócrates pudo morir varios meses después de la batalla.

Flavio Filóstrato, que escribe en torno al año 200 (dos siglos después de Dionisio) nos transmite en las Vidas de los Sofistas 17, la siguiente noticia:

$E$. Murió en Atenas con aproximadamente cien años y lo debemos considerar como a un muerto en batalla, porque murió después de Queronea al no poder soportar la noticia de la derrota ateniense.

La última fuente significativa sobre Isócrates es quizás la más tardía, pues se trata la vida anónima que aparece en los manuscritos copiada al principio de sus escritos y que algunos atribuyen a Zósimo de Ascalón, un gramático del siglo V/VI d. C. En ella leemos lo siguiente a propósito de la muerte de Isócrates:

$F$. Isócrates vivió según unos cien años, según otros noventa y ocho. Murió en el

73 La cifra de 4 días quizás deba corregirse en 14 de acuerdo con la indicación de la fuente $\mathrm{F}$ (cf. infra), aunque los autores han supuesto más bien lo contrario, ya que consideran que 14 días no pueden considerarse como "unos pocos".

74 Tucídides II 34. 
arcontado de Querondas después de la batalla de Queronea, lleno de dolor por la derrota y la desgracia que les sobrevino allí a los atenienses a manos de Filipo. Se dejó morir de hambre, según dice Demetrio, durante nueve días, pero según Afareo, durante catorce. Murió después de leer estos versos de tres dramas de Eurípides: «Dánao, el padre de cincuenta hijas», «Cadmo, que dejó otrora la villa de Sidón», «Pélope, hijo de Tántalo, al llegar a Pisa». Con ellos mostraba que, del mismo modo que aquellos, siendo bárbaros, se apoderaron de Grecia al llegar a ella, así este Filipo se convirtió en el cuarto dueño de Grecia... [tras una explicación sobre los personajes mitológicos citados concluye la vida:] Después de decir estos versos y morir, los atenienses, llenos

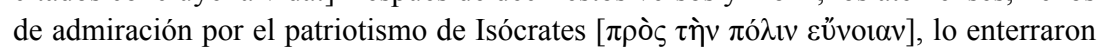
con honores a cargo del estado y esculpiendo una sirena de piedra la pusieron encima

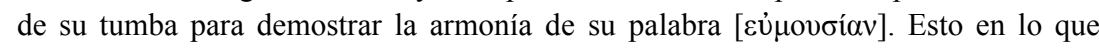
respecta a este divino orador.

La novedad de esta noticia, cronológicamente la más tardía de todas, es su prolijidad con respectos a las anteriores. No es de extrañar, puesto que el interés del autor es redactar una vida de Isócrates y no puede por lo tanto compararse con otros relatos incidentales anteriores, salvo quizás con la vida del Pseudo-Plutarco que contenía muchos detalles importantes sobre la vida de nuestro orador pero que en lo tocante a la muerte es menos precisa que F. Importante sobre todo es que este último testimonio indique las fuentes últimas de las que procede nuestra información sobre la muerte de Isócrates: su hijo Afareo y Demetrio de Falero, dos fuentes estrictamente contemporáneas de nuestro orador. Esta información no tiene por qué ser tardía al igual que la prolija explicación sobre el significado de los tres versos de Eurípides citados por Isócrates: nuestro anónimo autor simplemente da más detalles de sus fuentes que otros autores callaron por no considerar esencial extenderse en ellos, pero que probablemente conocieron.

Los defensores de la autenticidad de la carta III y de su datación en el 338 tras la batalla de Queronea no pueden admitir como válida la noticia de que Isócrates se dejó morir de dolor por la derrota ateniense pocos días después de la batalla, tal como indican claramente nuestras noticias A, B, C, D.1, E y F. Es evidente que una muerte así le habría impedido escribir la carta III felicitando a Filipo, por lo que consideran que es en la noticia D.2 donde debía estar inicialmente la verdad sobre la muerte de Isócrates. En esta noticia se dice efectivamente que Isócrates murió en el momento en que se celebraban los funerales por los caídos en Queronea, por lo tanto a fines del año 338 y meses después de acaecida la derrota ateniense. Según vieron todos los autores que analizaron el problema, Isócrates no habría podido escribir su carta III 
a Filipo inmediatamente después de la batalla, pues entonces Atenas vivió situaciones de pánico y emergencia ante la idea de que las tropas macedonias iban a dirigirse contra ella ${ }^{75}$. El discurso Contra Leócrates de Licurgo caracteriza perfectamente esta situación y nos documenta incluso la adopción de medidas drásticas como la prohibición de abandonar Atenas (que precisamente contravino Leócrates) o la de liberar a los esclavos y nacionalizar a los extranjeros para evitar disidencia interna (Contra Leócrates 41). Sólo meses después desaparecieron en Atenas los peores temores concebidos en los momentos posteriores a la batalla. Según sabemos por ejemplo por el epítome de Trogo hecho por Justino (IX.4) y por Polibio (V.10.1-6), Filipo se mostró en efecto generoso con los vencidos atenienses y firmó con ellos una paz ventajosa. Ya desde antes de que Filipo devolviese a Atenas los huesos de los caídos en Queronea, el clima era diferente entre ambos estados, de forma que es posible concebir que Isócrates pudiera haber escrito entonces una carta a Filipo con el optimismo que respira nuestra carta III $^{76}$.

Para explicar entonces que el resto de las noticias hablen de la muerte de Isócrates justo después de Queronea, los estudiosos recurren a distintas explicaciones. Así, consideran que Afareo se inventó ese relato de la muerte de su padre para caracterizarlo como un patriota y lavar su memoria manchada tras Queronea por su postura promacedonia ${ }^{77}$; o resaltan que la indicación de D.2 de que Isócrates murió tras cuatro o nueve días de ayuno es la original y que posteriormente esos días se pusieron en relación por error con la fecha de la batalla de Queronea ${ }^{78}$; o incluso señalan que no hay mención alguna a un suicidio voluntario en D.2 y que la muerte le pudo venir simplemente por la incapacidad de ingerir alimentos debido a una afección intestinal ${ }^{79}$. Final

75 Cf. ya esta observación en Wilamowitz, Aris. und Athen..., ob. cit., p. 396.

76 Wendland, ob. cit., p. 179-180; Mesk, ob. cit., pp. 22-23.

77 La idea fue apuntada por primera vez por Blass, «Isocrates' dritter Brief...», ob. cit., p. 112-113, que pensó que Afareo pudo haber escrito esa versión falsa sobre la muerte de su padre en un discurso judicial, ya que en este tipo de obras, según declara, la verdad no era precisamente lo que más importaba.

78 Una idea sugerida por Wilamowitz, «Unechte Briefe», ob. cit., p. 495 y ya aceptada por Blass, «Unechte Briefe», ob. cit., p. 35. Cf. también Wendland, ob. cit., p. 178; Mesk, ob. cit., p. 25 y Mathieu, Philippe..., ob. cit., p. 47

79 Hagen, ob. cit., (nota 2) p. 119 piensa que es una descomposición intestinal la enfermedad a la que Isócrates alude en Panatenaico 267 como la que le tuvo postrado tres años sin dejarle terminar el discurso y que es esa misma enfermedad la que le llevó a la muerte en el 338 ante la imposibilidad de digerir alimentos. Cf. también Mathieu, Philippe..., 
mente el hecho de que ninguno de los antiguos viera problema en atribuir a Isócrates la carta III y al mismo tiempo transmitir el relato "patriótico" de la muerte del orador tras Queronea, era solucionado por estos autores con la indicación de que los antiguos no pudieron ver quizás la contradicción porque ignoraban la fecha de la carta III $^{80}$. El carácter legendario de la muerte de Isócrates quedaría además probado por la historia inverosímil del recitado de los versos de Eurípides, que tiene todo el aspecto de ser un desarrollo posterior destinado a ennoblecer al personaje ${ }^{81}$.

Como se ve, los argumentos que descalifican el valor de toda la tradición biográfica y sólo admiten como válida la indicación de D.2 son en su mayoría bastante forzados. Admitiendo que la noticia de la muerte patriótica de Isócrates en el 338 haya podido ser "adornada" y ampliada en la tradición posterior (y que por lo tanto pueda ser falsa la historia del recitado de los versos de Eurípides), parece excesivo descalificarla totalmente en favor de una noticia tan breve como es la D.2, que además se halla a escasas líneas de la versión D.1 que confirma la noticia del suicidio patriótico de Isócrates: ambas salieron de la pluma del mismo autor y es difícil pensar que éste no supiera apreciar la contradicción entre las dos versiones, cuando el resto de su relato es por lo demás coherente y homogéneo. Por otro lado aun admitiendo que Afareo pudo inventarse una muerte patriótica para su padre ${ }^{82}$ ¿qué decir del aristotélico Demetrio de Falero, en nada sospechoso de ser partidario de nuestro orador? Ya Wilamowitz señaló el valor de estas dos fuentes independientes ${ }^{83}$ y parece excesivo descalificar su testimonio indicando que en puridad el texto F sólo presenta a Demetrio y a Afareo como fuentes de los días que duró la muerte de Isócrates, pero no del momento ni de las causas que la motivaron. Se trata de una explicación in extremis, pues es más que inverosímil que el

ob. cit., pp. 47-48.

80 Wendland, ob. cit., p. 178

81 Blass, «Isocrates' dritter Brief...», ob. cit., p. 112 y Mesk, ob. cit., p. 29-30 piensan que la anécdota pudo originarse de la lectura de Panatenaico 80 donde Isócrates cita la dominación de Grecia por Pélope, Dánao y Cadmo.

82 No obstante, si admitimos que la versión patriótica de la muerte de Isócrates estaba contenida en un discurso judicial (?) escrito por Afareo (tal como sugirió Blass) difícilmente se puede entender que desde allí pasara a convertirse en la única versión autorizada sobre la muerte del orador.

83 Wilamowitz, Aris. und Athen ..., ob. cit., pp. 395-396. 
redactor de F sacase de dos fuentes tan valiosas como Afareo y Demetrio sólo la indicación banal de los días que Isócrates tardó en morir: es probable que todo su relato se base en ambos autores (ya que no cita otras fuentes) y que sólo la discrepancia (menor) en los días que duró la agonía del orador motive su mención expresa. Se olvida también que hay otras fuentes antiguas como Hermipo que redactó una biografía de Isócrates ya en el siglo III a.C. de la que proceden sin duda muchas de las informaciones de autores posteriores, como por ejemplo Dionisio de Halicarnaso ${ }^{84}$. Por otro lado ¿cómo es posible pensar que se pudiera falsear la muerte de Isócrates de manera tan flagrante haciendo pasar por un "suicida patriota" al autor de una carta de aliento a Filipo tras la batalla de Queronea? La importancia de la figura de Isócrates hace inverosímil pensar que esta grosera manipulación pudiera haber pasado sin réplica en la tradición posterior, pues réplica no es la noticia D.2, cuyo origen, como pasaré ahora a considerar, es fácil de explicar a partir de las demás.

La noticia D. 2 no contiene en realidad ningún elemento nuevo con respecto a las demás, sino que es fruto de un sencillo error: el de hacer coincidir la fecha de la muerte de Isócrates con la fecha del funeral consagrado a su memoria. Según dicen todas las noticias recopiladas, Isócrates no pudo soportar la noticia de que Atenas fuera derrotada por Filipo y se dejó morir de hambre días después de Queronea. Este patriótico suicidio del orador hizo que se considerara que su muerte había acaecido, como señala Dionisio en A, junto a los

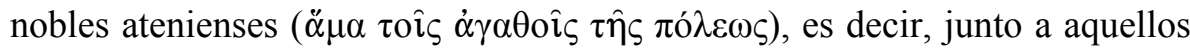
atenienses muertos en el campo de batalla de Queronea. Isócrates era pues un caído en combate más y por ello es lógico que cuando se celebraron las honras fúnebres oficiales por los muertos en Queronea al final de ese año, Isócrates fuera incluido en ellas. Que esta idea no es una pura especulación nos lo demuestra el testimonio E, que declara expresamente que se debe «considerar a Isócrates como a un muerto en batalla, porque murió después de Queronea al no poder soportar la noticia de la derrota ateniense». El testimonio F insiste incluso en este particular y escribe que «los atenienses, llenos de admiración por el patriotismo de Isócrates lo enterraron con honores a cargo del estado y esculpiendo una sirena de piedra la pusieron encima de su tumba para demostrar la armonía de su palabra». La existencia de la propia tumba con una efigie

84 Mathieu, Philippe..., pp. 48-49 va más allá de lo razonable cuando piensa que la indicación de Hermipo de que Isócrates escribió el $A$ Filipo poco antes de su muerte y de la del rey macedonio, hace en realidad referencia a la carta III. 
de sirena, conocida por innumerables autores de la Antigüedad (hasta el punto de que aludir a la "sirena isocrática" se convirtió en un proverbio) es simple prueba de la veracidad de esta versión.

Si con esta interpretación en mente volvemos al pasaje D.2, veremos que en realidad tal como está formulado presenta algún problema. En el pasaje se mezclan en efecto sin solución de continuidad dos criterios: uno que indica el número de días que duró la agonía y otro que hace referencia a los funerales de los caídos en Queronea, sin que esté claro cómo deben ponerse en relación ambos. No se entiende además la afirmación subsiguiente y aislada de que

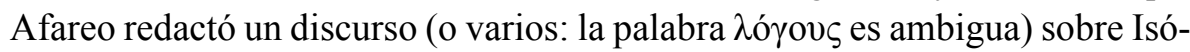
crates, porque no tiene relación con lo que se dice antes y después sobre la muerte del orador. Como además todo el texto de la Vita está muy corrompido (hay dos cruces en la edición de J. Mau a dos y cinco líneas de nuestro pasaje) es posible suponer que la frase que indica que Afareo "escribó los discursos de

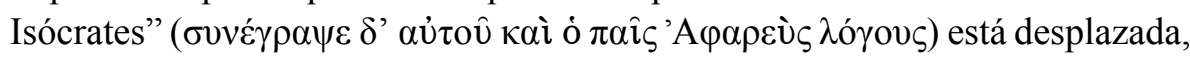
ya que se repite en $839 \mathrm{C}$ (ó $\delta$ ' 'A primimos esta frase, al igual que hace el editor con otra referida a Afareo unas líneas más adelante, la alusión a los discursos fúnebres por Queronea puede aplicarse entonces a la siguiente que empieza con غ̇ $\alpha_{\alpha} \varphi \eta$ y menciona el entierro de nuestro orador. Es posible también que hayan desaparecido algunas palabras en el lugar en el que se insertó por error la referencia a Afareo. Otra op-

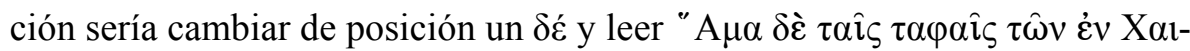

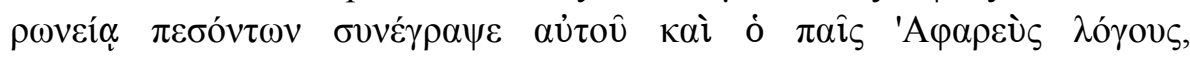
entendiendo "los discursos de Isócrates" como discursos en su honor compuestos por Afareo en el momento de su funeral oficial. En cualquier caso es claro que la mención a los funerales de Queronea no iba referida al día de su muerte, sino a la frase de étá $\varphi \eta$, lo que elimina toda sospecha de que existió una versión diferente de la muerte de Isócrates en la tradición biográfica antigua.

Por todo esto creo que se puede afirmar sin la menor duda que Isócrates se suicidó pocos días después de la batalla de Queronea ${ }^{85}$. La tumba que le

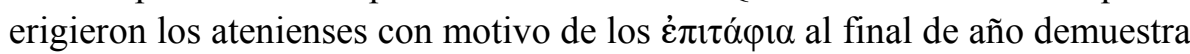

85 Es incluso posible que Licurgo, testigo de los momentos de angustia que se vivieron en Atenas cuando llegó a la ciudad la noticia de la derrota, tenga presente a nuestro orador cuando escribe que se podía ver vagar por toda la ciudad a viejos exentos del servicio militar, ancianos exhaustos al borde de la tumba, envueltos en su mantos dobles (Contra Leócrates 40). 
claramente que en los últimos momentos de su vida nuestro orador antepuso claramente sus convicciones patrióticas a sus sentimientos promacedonios: un camino que ya recorrió en el Panatenaico. Un escrito en favor de la política de Filipo después del 338 contradice lo que sobre nuestro orador dice unánimemente la tradición antigua, que desconoce por completo la existencia de una obra así.

\subsection{Autenticidad de la carta}

Son pocos los autores que han dudado de la autenticidad de la carta y la mayoría de ellos lo ha hecho no en función del estilo de la carta en sí (tal como ocurría con la carta IV dirigida a Antípatro), sino en función de la verosimilitud o no que tenía el hecho de que Isócrates se dirigiese laudatoriamente a Filipo después de la derrota de Queronea. Para ellos resulta imposible que Isócrates pudiera aprobar la política de Filipo en aquellos momentos, cuando acababa de derrotar a Atenas, sin que ello perjudicase su reputación de patriota (que, como vimos, se había labrado trabajosamente con la redacción del Panatenaico). Sin embargo este tipo de argumentos no tienen por qué afectar necesariamente la autenticidad de la carta, en la que, según analizaré en este apartado, desde el punto de vista de su formulación y de las ideas recogidas en ella no hay nada que nos indique que es falsa.

El único estudio que ha intentado negar la autenticidad de la carta III desde el punto de vista de estilo, el de Woyte ${ }^{86}$, ha sido incluso considerado poco convincente por Münscher ${ }^{87}$ e ignorado por Wilamowitz, a pesar de que ambos autores consideraban también la carta III una falsificación. Más contundente aún es el juicio de un autor como Wendland que considera poco correcto el proceder de Woyte, porque señala giros supuestamente no isocráticos como prueba de la falsedad de la carta, mientras que califica de imitación los que coinciden con el estilo de nuestro orador ${ }^{88}$.

En realidad, no hay nada en el estilo de la carta que esté en disonancia con el de Isócrates. Es más, son tantos los paralelos que pueden establecerse entre

86 C. Woyte, De Isocratis quae feruntur epistulis quaestiones selectae, Leipzig, 1907: no me ha sido posible consultar esta obra, una tesis doctoral de principios de siglo citada por diversos estudiosos de la época.

${ }^{87}$ Münscher, reseña a Wendland, ob. cit. (nota 70), col. 1348 lo califica de «nicht allzu überzeugend».

${ }^{88}$ Wendland, ob. cit., p. 178 nota 3. 
las ideas formuladas en la carta III y otros escritos isocráticos, que los defensores de su falsedad se ven obligados, como Treves, a calificarla de un "centón" de otros escritos del orador ${ }^{89}$. Sin embargo, una simple consideración de los pasajes con más ecos del estilo e ideas de Isócrates parece más bien convencer de lo contrario, es decir, de que la carta salió de la pluma de nuestro orador, dado que una compenetración tan estrecha con su obra no parece estar al alcance de cualquiera, tal como vimos al analizar la carta IV. Pero veamos algunos ejemplos del carácter isocrático de esta carta III.

Algunas alusiones a la obra de Isócrates estaban al alcance quizás de un simple conocedor de la obra de Isócrates y en concreto del discurso A Filipo, que fue objeto de duras críticas en ambientes platónicos tal como vimos por la carta de Espeusipo. Las referencias a la guerra contra el persa que aparecen en $\S 2$ son en efecto el motivo central de este discurso. Cuando un poco antes en el mismo párrafo de la carta se dice que en el A Filipo se intentó que el rey conciliase a Atenas con las ciudades de los lacedemonios, tebanos y argivos se tiene en mente un pasaje de este discurso, concretamente A Filipo 32-38, donde Isócrates recordó al rey los lazos históricos que le unían a estos cuatro estados y que le hacían la persona adecuada para conseguir reconciliarlos. Isócrates insiste en $A$ Filipo 36 que el rey tiene una oportunidad para ser útil a es-

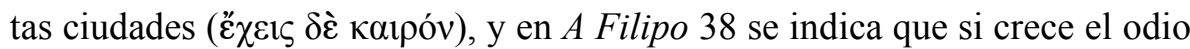

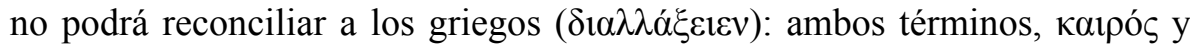
$\delta 1 \alpha \lambda \lambda \alpha ́ \sigma \sigma \omega$ aparecen de nuevo en este párrafo segundo de la carta recordándonos el discurso de Filipo. También la alusión a la vejez en $\S 4$ es tópica en los últimos discursos de Isócrates, y la encontramos en Panatenaico 268, carta I 1 y carta IX 16 expresada en similares términos y con el verbo $\alpha \pi \varepsilon i ́ p \eta \kappa \alpha$. Finalmente, la mención a personas de su entorno en $\S 3$ es un recurso frecuente del orador, tal como vimos en el propio Panatenaico: Isócrates solía responder en sus discursos a las opiniones o dudas que le formulaban sus allegados como medio de romper el monólogo del discurso escrito ${ }^{90}$. Aunque estos rasgos no bastan para probar la autenticidad de la carta, es claro que nos indican que su autor estaba cuando menos compenetrado con la obra de Isócrates.

Hay sin embargo dos sutiles reenvíos al A Filipo que no son a mi entender comprensibles desde el punto de vista de un falsificador, ya que tienen que

89 Treves, ob. cit. (nota 70), pp. 311-312.

90 Para estos problemas cf. S. Usener, Isokrates, Platon und ihr Publikum. Hörer und Leser von Literatur im 4. Jahrhundert v. Chr., Tübingen, 1994. 
ver con reflexiones generales sobre modos de comportamiento y no con características específicas del mensaje del $A$ Filipo que pudieran ser fácilmente identificadas. Se trata en primer lugar de $\S 4$, que recoge en términos casi idénticos una afirmación contenida en A Filipo 135. Basta con comparar ambos pasajes:

Carta III.4

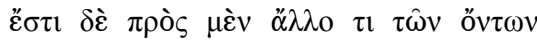

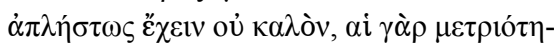

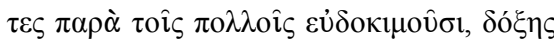

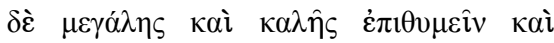

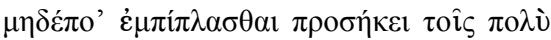

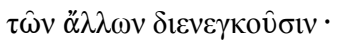

\section{A Filipo, 135}

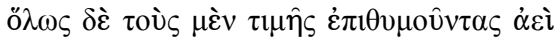

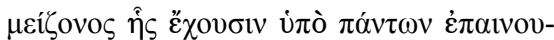

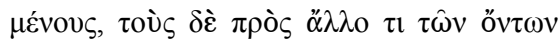

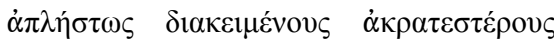

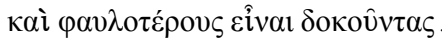

Idéntico paralelo se observa entre otros dos pasajes de la carta y del discurso:

Carta III.5

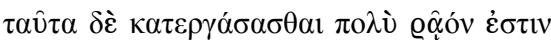

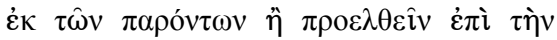

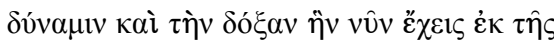
$\beta \alpha \sigma i \lambda \varepsilon^{\prime} \alpha \varsigma \tau \hat{\eta} \varsigma \dot{\varepsilon} \xi \dot{\alpha} \rho \chi \hat{\eta} \varsigma \dot{u} \mu \hat{\imath} v$ ن் $\pi \alpha \rho \xi \dot{\alpha} \sigma \eta \varsigma$.
A Filipo 115

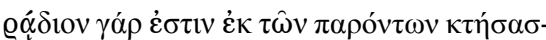

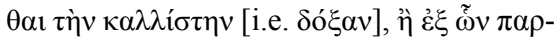

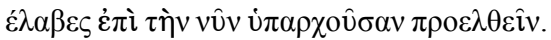

Los paralelos entre estos dos pasajes no deben llevarnos sin embargo a la errónea conclusión de que aquí está actuando un falsario que se inspira en el A Filipo para redactar su carta: es costumbre de Isócrates repetir constantemente ciertas ideas en sus obras. Las palabras que utiliza son además, aunque muy próximas, no idénticas, lo que indica que es la idea lo que fundamentalmente repite el autor, no su formulación, aunque la primera lleva inevitablemente a la segunda. Lo único que quizás pueda resultar un tanto chocante es la razón de recordar con tanta insistencia en esta carta III ideas o expresiones presentes en el A Filipo. Una razón de ello puede estar precisamente en el hecho de que ambos escritos se redactaran a escasa distancia uno de otro, tal como defenderé en el apartado siguiente.

La única idea que parece desentonar de las opiniones de nuestro orador se encuentra recogida en §5, donde Isócrates escribe, dirigiéndose a Filipo, que si éste cumple sus objetivos derrotanto al persa, "nada quedará ya sino que te

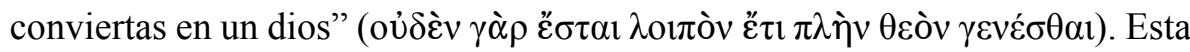
indicación, interpretada literalmente, choca con las afirmaciones de Isócrates en el $A$ Filipo 113-115 y 151, como bien señala Rue van Hook en nota a la edi- 
ción de Loeb. Allí en efecto nuestro orador niega a los reyes la posibilidad de alcanzar la condición de dioses. Pero por encima de esta contradicción interna, la "divinización" de Filipo resulta escandalosa en boca de un ateniense del momento, por más que el camino que conduce a la divinización de los gobernantes con Alejandro esté próximo y por más que sea en Atenas donde se concedió en el 307 por primera vez honores divinos a un gobernante en las personas de Demetrio Poliorcetes y su padre Antígono ${ }^{91}$. Wilamowitz ya vio en esta divinización de Filipo uno de los principales obstáculos para considerar auténtica la carta y pensó que fue redactada en tiempos de Alejandro ${ }^{92}$. Esta dificultad puede obviarse si consideramos que lo que está afirmando aquí Isócrates es que la mayor gloria que puede obtener Filipo se la proporcionarán sus campañas persas, puesto que el ser dios es algo que cae fuera de su alcance. Esta interpretación viene avalada por un análisis de Fritz Taeger ${ }^{93}$ que considera que la afirmación de Isócrates tiene un claro valor gnómico precisamente en este sentido. Además la frase en cuestión aparece en los manuscritos, no donde la escriben los editores (y allí todavía plantea problemas), sino en un lugar en el que carece de sentido, justo al final del primer párrafo, detrás de la palabra $\dot{\pi} \pi \rho \xi \xi \dot{\alpha} \sigma \eta \varsigma$, lo que hace pensar que pudiera haberse deslizado como una glosa en el texto ${ }^{94}$.

Pero si no hay por lo tanto nada desde el punto de vista de las ideas que descarte la autoría de nuestro autor, desde el punto del estilo todo parece encajar con el lenguaje de Isócrates. Todas las palabras utilizadas son normales en su

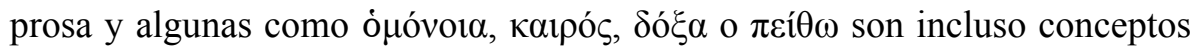
clave de su obra. Si comparamos el uso de determinados términos que aparecen en esta carta con el que presenta el resto de su obra y la de Platón (por escoger un contemporáneo con un amplio corpus de textos), veremos que el

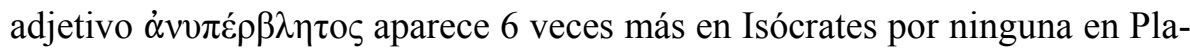
tón; que el verbo $\pi \alpha \rho o \xi v v \omega \omega$ se encuentra otras 7 veces más en Isócrates por una sola en una epístola de Platón; que $\varepsilon i \lambda \omega \tau \varepsilon v ́ \omega$ y $\dot{\varepsilon} \mu \pi \imath \pi \lambda \alpha ́ v \omega$ son inéditos en Platón, mientras que aparecen otra vez más cada uno en los escritos isocrá-

91 Plutarco, Demetrio 10-12 y Diodoro Sículo XX.46.1-3.

92 Wilamowitz, Aris. und Athen, ob. cit., p. 397, nota 7.

93 F. Taeger, «Isokrates und die Anfänge des hellenistischen Herrscherkultes», Hermes 72, 1937, pp. 355-360.

94 Wagner, ob. cit., p. 8. 
ticos; y que $\dot{\varepsilon} \xi \alpha \rho \kappa o v ́ v \tau \omega \varsigma$ aparece otras dos veces más en Isócrates por un solo caso en Platón... Desde el punto de vista de la lengua, si hubiera que hablar de falsificación, sólo podría decirse que ésta es tan próxima al original que sólo es concebible dentro del círculo de sus más íntimos discípulos.

Pero aún admitiendo que la carta hubiera podido ser falsificada y que el estilo e ideas de Isócrates hubieran podido ser imitados de manera tan exacta por algún allegado a él, faltaría por probar cuál pudo ser el motivo de semejante falsificación. El único posible (no me consta que se hayan sugerido otros) fue apuntado por Wilamowitz ${ }^{95}$ que pensó que la carta sólo pudo haber sido fraguada en el bando promacedonio después de Queronea para demostrar que las simpatías de Isócrates hacia Filipo se habían mantenido después de la derrota ateniense. Según Wilamowitz con esta carta los partidarios de Filipo habrían querido hacer frente a la historia, inventada por los enemigos de Macedonia, de que Isócrates en el momento de su muerte había "estigmatizado" a Filipo mediante la cita de tres versos de Eurípides que identificaban al rey con a un bárbaro conquistador semejante a Pélope, Cadmo y Dánao. El erudito alemán, aunque creía en el suicidio del orador tras Queronea, no concedía en efecto crédito a la historia de las últimas palabras de Isócrates en el momento de su muerte. Estoy de acuerdo con Wilamowitz en que el único momento posible en el que tenía sentido falsificar una carta promacedonia de Isócrates era el inmediatamente posterior a Queronea, pero realmente es más que extraño que el supuesto falsificador no hiciese mención alguna a la preocupación de Isócrates por su ciudad derrotada y le hiciese hablar en términos tan distantes y vagos acerca de los recientes sucesos, algo que no cuadra con el procedimiento de un falsificador que busca siempre autentificar su carta con referencias concretas. Por otra parte, si una falsificación como ésta hubiese sido divulgada ¿no habría sido detectada de inmediato? ¿no hubiera habido una respuesta por parte de los allegados al orador? Y sin embargo, no hay una sola palabra de polémica acerca de este asunto en toda la tradición antigua, tan rica en detalles sobre la muerte y la familia del orador, tal como nos muestra el texto del Ps.Plutarco. Por todo ello lo lógico es pensar que la carta III es auténtica.

\subsection{La propuesta de Philipp Wagner}

95 Wilamowitz, Aris. und Athen ..., ob. cit., p. 397. 
Un análisis de la tradición biográfica nos ha demostrado que Isócrates se suicidó en el 338 a escasos días de la derrota ateniense en Queronea, mientras que el tenor de la carta III a Filipo confirma claramente que fue escrita por la pluma de Isócrates. Llegados a este punto parecemos encontrarnos en el mismo callejón sin salida en el que se encuentra la crítica y sin embargo nos hallamos más cerca que nunca de la solución, que no puede pasar sino por admitir la autenticidad de la carta y de la tradición biográfica y proceder a una redatación de la carta III. La hipótesis que ahora voy a proponer no es sin embargo novedosa, ya que fue defendida en 1875 por Philipp Wagner, pero desgraciadamente no tuvo eco alguno entre sus contemporáneos, ya que se publicó en un Programm del gimnasio de Jever, una pequeña localidad de los confines de la Frisia alemana, y ninguno de los estudiosos que ha dedicado su atención al problema parece haber leído su argumentación. La propuesta de Wagner es sin embargo certera, pues propone datar la carta al final del año 346. Sus sucintos argumentos, ya inaccesibles para sus contemporáneos, se basan fundamentalmente en el análisis del contexto histórico en el que se sitúa la carta. Los recogeré en nota al hilo de mi exposición y a ellos añadiré otros nuevos argumentos, de forma que resultan ocho puntos a favor de la datación en el año 346:

1. El silencio sobre Atenas. Entra dentro de lo posible que Isócrates escribiera a Filipo después de Queronea cuando éste mostraba una política generosa hacia Atenas. Menos probable es que después de la derrota de su patria Atenas por Filipo en un enfrentamiento armado Isócrates se agarrase a la convicción de que Filipo podía seguir siendo el que mejor podría unir a los griegos, cuando precisamente la batalla era la prueba palpable de su desunión. Es además el propio Isócrates el que en la carta VI.3, ante la simple posibilidad de un conflicto de intereses entre su ciudad y otro estado, se encuentra obligado a tomar partido por su ciudad de antemano, ya que, según dice, en caso contrario se vería acusado de faltar a sus obligaciones. Pero incluso admitiendo que Isócrates hubiera preferido su lealtad a Filipo frente a su condición de ateniense, lo que ya resulta absolutamente inconcebible es que hubiese escrito tras Queronea sin mencionar en un solo momento a su ciudad ni indicar a Filipo cómo debía comportarse con los vencidos atenienses, cómo debía administrar la victoria y superar los recelos hacia él. Dicho de otro modo: lo que realmente choca en la carta no es tanto la alabanza a Filipo sino el absoluto silencio de Isócrates sobre su ciudad, derrotada y humillada en Queronea. Este silencio no sólo es absolutamente impensable en una carta escrita supuestamente en tan críticos momentos, sino que arruina la labor que Isócrates intentó hacer en el Panatenaico, que en la segunda entrega de este estudio demostramos que era una defensa por parte de Isócrates de su patriotismo ateniense con el fin de librarse de las acusaciones que habían recaído sobre él por la redacción del $A$ Filipo. ¿Cómo es posible que Isócrates, después de vindicar su patriotismo en el 
Panatenaico pueda componer una carta entusiasta a Filipo sin aludir siquiera con una sola palabra a la situación de la Atenas derrotada? La $\delta$ ó $\xi \alpha$ de Isócrates, su propio prestigio como patriota que ya vimos era una de las cosas que más le importaban, se habría visto definitivamente arruinado de haber escrito una carta como esta en el año $338^{96}$, en la que todas las palabras son de alabanza a Filipo y no hay ninguna alusión a su patria. Por ello parece difícil que Isócrates pudiera escribir esta carta en el 338, aunque no hay ningún obstáculo para suponer que pudiera haberla escrito en otro momento próximo a la redacción del $A$ Filipo.

2. La tradición antigua sobre la carta. La tradición antigua, probablemente desde la época de Dionisio de Halicarnaso, conocía la carta III a Filipo y la versión sobre el suicidio de Isócrates después de Queronea ${ }^{97}$, y sin embargo ningún autor antiguo apreció contradicción entre ambas. Es un recurso fácil decir, como hace Wendland ${ }^{98}$, que como la tradición en la que se basaba Dionisio no sabía en qué fecha se escribió la carta no pudo apreciar la contradicción entre ella y el suicidio de Isócrates tras el 338. En realidad es bastante sospechoso que nadie entre todos los autores antiguos se preguntase jamás sobre la fecha en que pudo ser escrita la carta. Lo más razonable es pensar por el contrario que sí lo hicieron, pero que su conclusión fue diferente a la de la mayoría de los investigadores modernos, es decir, que ningún antiguo pensó que la carta fue escrita en el 338, entre otras razones porque ello entraba en contradicción con el suicidio de Isócrates tras Queronea. Es más, en dos de los manuscritos del siglo XV que nos transmiten las cartas de Isócrates ${ }^{99}$, la carta III aparece situada, no detrás de la carta II también dirigida a Filipo en el año 344/343, sino antes de ella. El hecho de que el poseedor de estos códices sea un filólogo de primera fila como Constantino Láscaris, al que Teresa Martínez Manzano ha dedicado dos magníficas monografías ${ }^{100}$, hace pensar que el cambio no es azaroso sino fruto de una reflexión sobre la cronología de las cartas que llevó al copista a situar la carta III en un momento anterior al de la II. Si esta inferencia es correcta, entonces la carta III se escribió antes de 345/344.

3. Isócrates y Antípatro ( $\$ 1)$. Si Isócrates murió pocos días después de Queronea, como admite por unanimidad toda la tradición biográfica, es evidente que no tuvo ni tiempo ni ocasión para redactar una carta en la que, como él dice en $\S 1$, ha hablado con Antípatro sobre la paz antes de escribir a Filipo. Dejando aparte que la enfermedad se lo impedía, Antípatro había llegado a Atenas en el 338 dos meses después de Queronea para negociar la paz, cuando Isócrates estaba ya muerto. Sin embargo si datamos la

96 Si Isócrates tenía miedo de escribir a Antípatro cuando Atenas y Macedonia estaban en guerra e incluso pensaba que era peligroso en años anteriores ¿cómo es posible pensar que escribe una carta tan entusiasta a Filipo después de Queronea?

97 Sólo Focio menciona expresamente la existencia de dos cartas a Filipo, pero sus datos están apoyados en Dionisio de Halicarnaso y en Cecilio de Caleacte.

98 Wenland, ob. cit. p. 178.

99 Vat. gr. 1353 y Matr. 7210.

100 T. Martínez Manzano, Konstantinos Laskaris, Humanist, Philologe, Lehrer, Kopist, Hamburgo, 1994 y Constantino Láscaris, semblanza de un humanista bizantino, Madrid, 1998. 
carta en el 346 entenderemos que las conversaciones de Isócrates con Antípatro se desarrollaron en ese año, pues entonces el embajador de Filipo estuvo en Atenas para negociar con las autoridades atenienses la paz llamada de Filócrates. Es a estas conversaciones con Antípatro a las que se refiere probablemente Isócrates. No parece además verosímil que en el 338 Isócrates participase en conversaciones con Antípatro después de la derrota de Queronea, cuando el macedonio había derrotado a Atenas y estaba ya seguro de su política, mientras que es más probable que esas conversaciones se llevaran a cabo en el 346, cuando Filipo intentaba todavía evitar la confrontación con Atenas a través de la paz y necesitaba apoyo y consejo entre los sectores promacedonios atenienses.

4. La idea de una campaña contra el persa $(\$ 3)^{101}$. En el párrafo tercero de la carta Isócrates indica que sus contemporáneos le preguntaban de quién había surgido la idea de una campaña contra el persa, si de Filipo o de él, a lo que Isócrates responde que no lo sabe exactamente, porque no había tratado antes con el rey de Macedonia. Esta indicación es incomprensible en el 338 por dos motivos. En primer lugar Isócrates tenía relación con Filipo desde ocho años antes de esa fecha, ya que en el 346 le escribió un discurso, el A Filipo. En segundo lugar, en el año 338 eran ya de sobra conocidas desde años las intenciones de Filipo de llevar a cabo una campaña contra los persas, por lo que resulta extraño que sea ahora cuando los atenienses le pregunten a Isócrates sobre quién de los dos, si el orador o el rey, tuvo primero la idea de esa campaña. Estas inquietudes son por otra parte inexplicables de parte de unos atenienses inmersos en el aftermath de Queronea. Semejantes afirmaciones encajan sin embargo mucho mejor en el año 346, ya que es precisamente a finales de ese año cuando Filipo difundió por primera vez sus intenciones acerca de una campaña contra el persa ${ }^{102}$. La fuente de esta información es Diodoro de Sicilia XVI.60.4-5, que señala que cuando acabó la III Guerra Sagrada en el 346 Filipo regresó a Macedonia no sólo

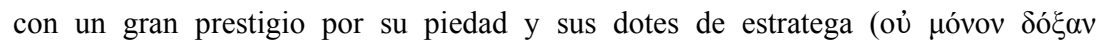

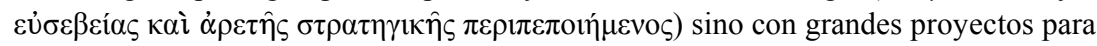

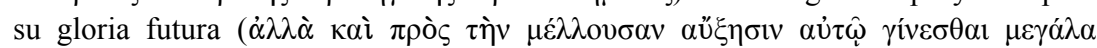

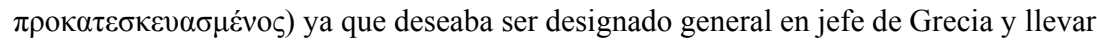

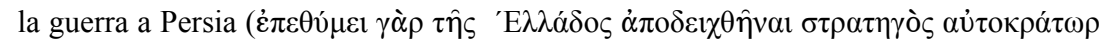

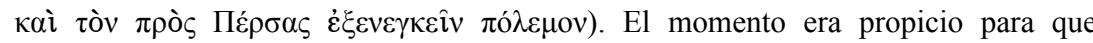
Isócrates escribiera al rey una carta recordándole que los planes a los que le instó en el A Filipo hacía unos meses, eran ahora más factibles que nunca.

5. La ausencia de mención al Panatenaico (\$6). Los que defienden que la carta se escribió en el 338 tienen que admitir necesariamente que el Panatenaico no es una defensa encubierta de la política de Filipo, pues en ese caso Isócrates lo habría

101 Wagner, ob. cit., p. 12: «Hoc postremo dicatur ad sententiam fulciendam, jam anno

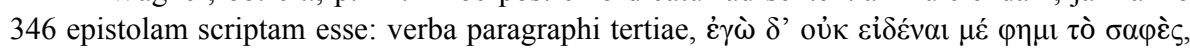

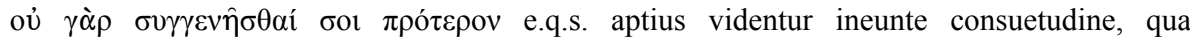
intercederet inter Philippum atque Isocratem, dicta esse quam exeunte».

102 J.R. Ellis en Cambridge An. History, ob. cit., p. 761. 
mencionado en esta carta, donde hace mención en $\S 6$ al Panegírico y al Filipo como dos discursos que apoyan la política que ahora defiende Filipo. Ahora bien, si el Panatenaico es un simple discurso de vindicación patriótica, tal como yo he defendido, y por lo tanto no es pertinente citarlo en este contexto, nos encontramos entonces frente al problema que he planteado en el punto 1: ¿cómo es posible que Isócrates arruine la labor de defensa de su patriotismo emprendida en el Panatenaico con una carta que ignora por completo la difícil situación de su polis?

6. Las referencias al discurso A Filipo $(\$ 1 \text { y } 6)^{103}$. Hay en la carta dos ocasiones en las que el orador hace referencia a su discurso A Filipo, escrito en el 346: una en el comienzo y otra en el final de la carta. En la primera ocasión, en $\S 1$ dice Isócrates a Filipo que después de hablar con Antípatro sobre lo que convenía hacer, quiso también escribir al rey algunas consideraciones "similares a las que éstan escritas en el dis-

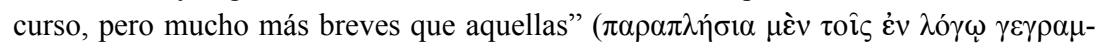

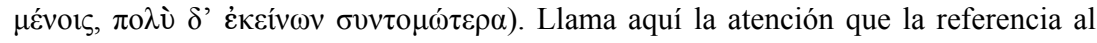
discurso A Filipo sea tan imprecisa. Si Isócrates hubiera escrito estas palabras en el año 338 ¿quizás no hubiera necesitado aclarar que el discurso al que se refería era el $A$ Filipo, escrito nada menos que 8 años antes? De hecho entre el 346 y el 338 Isócrates escribió otras obras, como el propio Panatenaico. La situación política había cambiado además bastante durante esos ocho años. Por otra parte, un discurso como su Panegírico, aunque muy anterior al $A$ Filipo (se escribió en el 380), contenía ideas panhelénicas como las que se van a tratar en esta carta III, por lo que, a falta de mayores indicaciones, un lector de esta carta podría pensar que Isócrates se refería a él, ya que, al fin de cuentas, es la obra más importante del orador.

Confirma esta idea el hecho de que el propio Isócrates haga referencia al Panegírico en $\S 6$ al final de esta carta, cuando señala que ve ahora realizadas y espera que se cumplan cuantas ideas «concebí siendo joven y me propuse escribir en el discurso Panegírico así como en el que te envié». Como ya señaló Wagner, Isócrates no pudo decir que era joven cuando escribió el $A$ Filipo, pues tenía entonces más de noventa años, pero tampoco cuando casi sexagenario publicó el Panegírico, por lo que se entiende que en esta frase Isócrates distingue entre las ideas que tuvo de joven y los discursos que escribió para defenderlas, ya en la madurez (Panegírico), ya en la vejez (A Filipo). En cualquier caso contrasta aquí la precisión con la que se refiere al

103 Blass, «Isokrates' dritter Brief...», ob. cit., p. 110 pensó que la carta III no pudo escribirse tras la paz del 346 pues según él Isócrates indica en el párrafo 6 de la carta haber compuesto el $A$ Filipo, escrito en el 346, cuando era mucho más joven. A ello replica Wagner, ob. cit., pp. 11-12: «Neque intelligendum, quid Blassius paragrapho extrema censeat

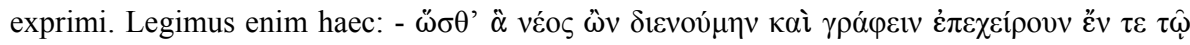

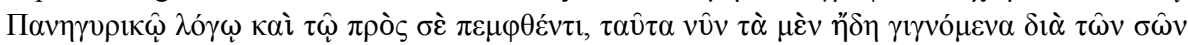

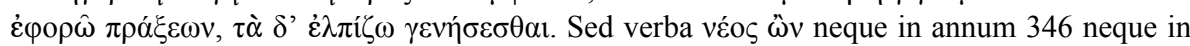
eum, quo Panathenaicus compositus est (annum 380 dico) quadrant. Cuius enunciati imo haec est sententia: ea, quae iuvenis animo mecum reputabam, quae oratione cum media aetate eram et altera oratione senex exprimebam, haec nunc spe celerius in eo sunt, ut perficiantur». 


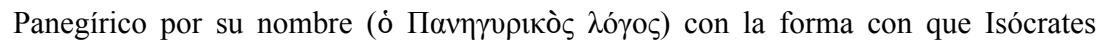

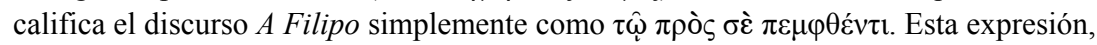
a mi entender, no debe considerarse como el "título" del discurso, ya que el verbo $\pi \varepsilon \dot{\varepsilon} \mu \pi \omega$ no recoge la "dedicatoria" a Filipo, sino simplemente señala que el discurso le fue "enviado" a Filipo. La espontaneidad de ambas expresiones sugiere que la carta fue enviada en un momento lo suficientemente cercano en el tiempo al de la redacción y envío del discurso A Filipo como para que no fuera necesaria mayor precisión sobre la identidad de éste. Pienso por lo tanto que sólo por esta circunstancia la fecha del 346 se hace más verosímil que la del 338 para la redacción de la carta.

7. El conflicto al que se hace mención $(\$ 2)^{104}$. En $\S 2$ Isócrates hace mención a que

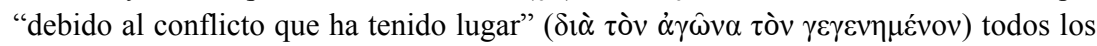
griegos se han visto obligados a actuar de manera sensata y a tener presentes los planes de Filipo, dejando de lado sus ambiciones y locuras para concentrarse en la guerra contra Asia. Todos los estudiosos han pensado que esto es una clara alusión a Queronea, pero esta hipótesis plantea serios problemas en la interpretación del pasaje. En primer lugar la palabra $\dot{\alpha} \gamma \omega ́ v$ no parece la apropiada para referirse a la guerra que han sostenido tebanos y atenienses contra Filipo. Para las guerras Isócrates emplea la palabra $\pi \delta ́ \lambda \varepsilon \mu \circ \varsigma$ que es incluso la que utiliza en este mismo párrafo para designar la guerra contra el persa. La palabra $\dot{\alpha} \gamma \omega \dot{v}$ en Isócrates se utiliza sobre todo en un sentido judicial o para referirse competiciones cívicas en casi 3 de 4 casos y cuando se aplica a enfrentamientos entre estados (en un sentido que comprende y supera al del mero combate por las armas), aparece siempre junto a la palabra $\pi$ ó $\lambda \varepsilon \mu \varsigma_{\zeta} \mathrm{u}$ otras similares para precisar que el conflicto es armado ${ }^{105}$. En segundo lugar, no se entiende el sentido que puede tener en el año 338 que Isócrates diga que "todos" los griegos ( $\pi \alpha ́ v \tau \varepsilon \varsigma$ se

104 Wagner, ob. cit., p. 11: «Nihil igitur restat, nisi ut anno 346 scriptam eam [carta III] esse putemus, cum foedere cum Palaeco facto, Phocensibus deuictis, Philippo in societatem Amphictyonum assumpto, pax cum Atheniensibus mense martio constituta et iunio iureiurando firmata erat, quo tempore optima quaeque sperabat Isocrates, ciuitates Graecas discordia diutina fessas beneuolentissimo ac potentissimo Macedonum rege adiuuante denuo corroboratum iri ratus. Cumque orationem suam eo tempore ad Philippum daret, quo Phocenses nondum pacati erant, eius quasi appendiculam misit epistulam. Qua nimium sperare Isocratem non est mirandum, utpote qui reipublicae regendae haud ita gnarus esset»; p. 12: «Vnum argumentum plus auctoritatis habere uidetur: cum Phocenses deuincerentur, omnino proelia non esse commissa. Attamen licet illas intellegere pugnas, quibus ante bellum a

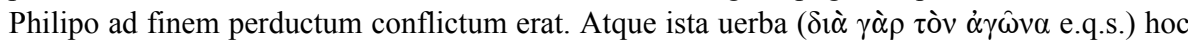
fere sibi uelle puto: postquam per decem annos Graeci aequo Marte inter se pugnauerunt, nunc uidentes a rege bellum sine uulnere esse confectum, resipiscere coguntur, cum intellegant infirmos se ipsos esse atque inualidos. Melius mihi placeret enunciatum illud, si

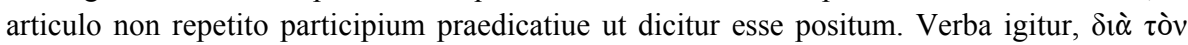
$\dot{\alpha} \gamma \hat{\omega} v \alpha \gamma \varepsilon \gamma \varepsilon v \eta \mu \varepsilon ́ v o v$ in nostram linguam uerteremus: in Folge der Beendigung des Kampfes; sed ne illa quidem explicandi ratio absona uidetur».

${ }^{105}$ Cf. A Nicocles 49, Encomio a Helena 17, Panegírico 99 y 165, Panatenaico 155. Cf.

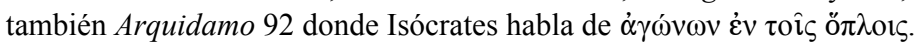


aplica a los griegos y no incluye a los macedonios, según la interpretación general) están ya convencidos de que deben abandonar sus enfrentamientos mutuos. En efecto, si en el 338 los griegos, tebanos y atenienses habían dejado de lado sus enfrentamientos mutuos, ello fue antes de la batalla y precisamente para coaligarse contra Filipo. Pero aunque el "todos" al que hace referencia el texto incluya a Filipo y los griegos a la vez, parece sorprendente que se califique este enfrentamiento de $\mu \alpha v i ́ \alpha$ y, sobre todo, de $\pi \lambda \varepsilon$ ov $\varepsilon \xi i ́ \alpha$ cuando los ejércitos de Filipo estaban luchando en Beocia, en las propias puerta de Atenas. Pienso por lo tanto que la alusión encaja mucho mejor en el año 346, cuando todos los griegos estaban divididos respecto a la actitud que debía tomarse frente a Macedonia y la cuestión de la III Guerra Sagrada caldeaba los ánimos. Isócrates utiliza la palabra $\dot{\alpha} \gamma \omega ́ v$ y no $\pi$ ó $\ell \varepsilon \mu \rho \varsigma$ para referirse a las tensas negociaciones entre Atenas y Filipo a lo largo de todo el año 346 (hubo hasta cuatro embajadas entre ambos poderes) y que condujeron en abril a la firma de la llamada paz de Filócrates con Macedonia, en junio a su ratificación por Filipo y en agosto al acuerdo para poner fin a la III Guerra Sagrada. Esta última en concreto enfrentó a la mayoría de los estados griegos en torno a la solución que debía darse a la ocupación focia de Delfos que había desencadenado el conflicto en el año 355 y había obligado a prácticamente todos los estados griegos a alinearse, bien con Tebas, bien (como Atenas) con los focios. El acuerdo que los miembros de la Anfictionía tomaron a principios de agosto del 346 acerca de cómo castigar el "sacrilegio" de los focios, aunque no satisfizo a Atenas (hubo tensiones en los meses siguientes) supuso cerrar un prolongado periodo de conflictos. El propio Demóstenes defendió el acuerdo en su discurso Sobre la Paz con el fin de evitar una nueva guerra contra Filipo. Para Isócrates los acuerdos tomados entonces reflejan la sensatez de los griegos, que han sabido reaccionar ante la gravedad del conflicto ("obligados" en cierto modo por la situación) y conseguido ponerse de acuerdo dejando sus enfrentamientos de lado.

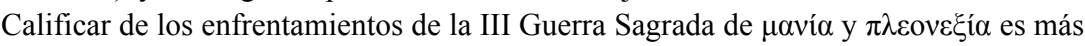
que acertado. La "locura" de los contendientes que designa la palabra $\mu \alpha v i ́ a$ caracteriza muy bien la falta de lógica que llevó al enfrentamiento por el control de

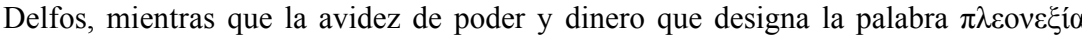
hace referencia a las ambiciones injustificadas de todos los estados y las claras motivaciones económicas que determinaron el conflicto, en el que los focios habían utilizado los tesoros de Delfos para pagar a mercenarios.

8. Las circunstancias en que se compusieron la carta III y el discurso A Filipo. Si a la luz de todas las consideraciones anteriores, partimos entonces de la idea de que la carta se compuso a finales del 346, habrá que explicar entonces por qué en esta carta se subrayan de manera tan marcada las diferencias que existían en el momento de su redacción con respecto al del discurso A Filipo que se compuso también ese mismo

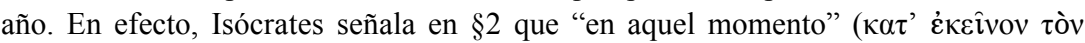

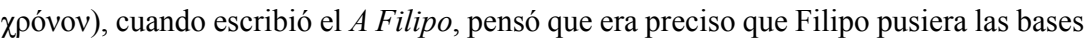
de la concordia entre los griegos después de haber reconciliado a Atenas con Esparta, Tebas y Argos, pero que "entonces las circunstancias eran diferentes" ( $\tau$ ó $\varepsilon \varepsilon \mu \grave{\varepsilon} v$ oûv

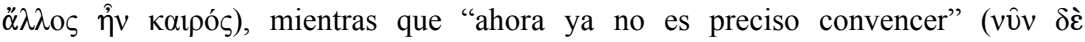


$\sigma v \mu \beta \varepsilon \beta \eta \kappa \varepsilon \mu \eta \kappa \varepsilon ́ \tau ı ~ \delta \varepsilon i ̂ v ~ \pi \varepsilon i ́ \theta \varepsilon ı v)$ ya que todos se han visto obligados por el conflicto pasado a poner fin a sus discrepancias. Como ya vimos en el punto anterior, este momento presente se refiere a un momento posterior al fin de la III Guerra sagrada, es decir Agosto del 346. Por las consideraciones hechas en el punto 4, pienso que Isócrates escribió esta carta sólo después de la divulgación de los propósitos de Filipo de marchar contra el persa, tal vez en los últimos meses del año 346 o incluso a comienzos del 345. El discurso A Filipo se compuso en cambio con motivo de la paz entre Filipo y Atenas ratificada en Abril del 346, pero en cualquier caso antes de Julio de ese mismo año, ya que en A Filipo 55-56 se habla del enfrentamiento que sostienen todavía los focios y los tebanos con motivo de la III Guerra Sagrada y en A Filipo 74 se indica que no está resuelto aún. Suponiendo por lo tanto que el $A$ Filipo se enviara a Filipo en torno a mayo del $346^{106}$ y la carta III seis o siete meses después, se puede decir que las circunstancias habían cambiado lo suficiente entre ambas fechas como para que Isócrates en la carta III pudiera ver con más optimismo una paz que en mayo estaba todavía en el aire y pendiente de ratificación final por Filipo, pero a la que a final de año no se oponía ni siquiera Demóstenes. No me cabe duda en efecto que es al partido de Demóstenes al que hemos de ver detrás de las alusiones a los demagogos enemigos de la paz hechas en A Filipo 73-80.

\section{Conclusiones.}

Como consecuencia del análisis realizado en las páginas anteriores podemos establecer el siguiente orden cronológico de las obras escritas por Isócrates desde la redacción del A Filipo en el 346 hasta su muerte en el 338:

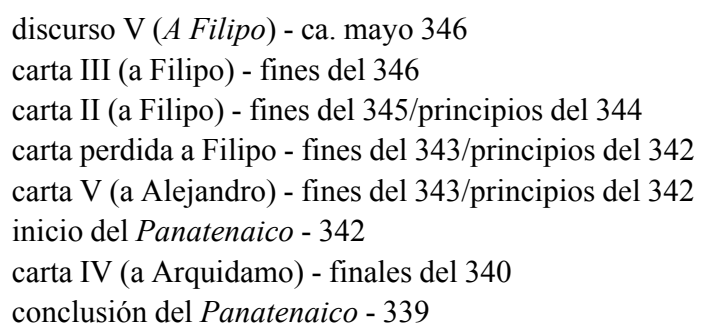

Esta ordenación de sus obras tiene importantes repercusiones a la hora de valorar las ideas del orador. Podemos así concluir que después de la redacción del A Filipo en la primavera del 346 Isócrates envió en los siguientes años por lo menos tres cartas al rey, de la que se nos conservan dos. La primera de ellas (carta III) es de finales del 346 y muy optimista, e insta al macedonio a

106 Blass, Attische Beredsamkeit, ob. cit., vol. II, p. 314 piensa que Isócrates comenzó a escribir su discurso A Filipo ya en Abril del 346, nada más aceptada la paz con Macedonia por la asamblea: esta es hoy la communis opinio sobre el particular. 
emprender la campaña contra el persa ahora que las circunstancias eran más favorables que meses antes cuando todavía la III Guerra Sagrada estaba en curso. La segunda carta, escrita antes de la campaña Tesalia de verano del 344, es más larga y motivada por la inquietud que provocan en Isócrates las graves heridas que tuvo Filipo en el combate con los ardieos de la Dalmacia. $\mathrm{Su}$ tono es más pesimista e Isócrates no deja de referirse en ella a las críticas que ciertos sectores atenienses (ligados sin duda a Demóstenes) vierten tanto contra él como contra el rey. La carta refleja el creciente desencanto con la paz de Filócrates producido durante el año 345. La tercera carta a Filipo no se conserva, pero debió de escribirse a fines del 343 o principios del 342 , ya que acompañaba a la carta $\mathrm{V}$ que Isócrates escribió por esas fechas. No sabemos qué pudo haber escrito entonces Isócrates al rey, aunque dado el creciente clima antimacedonio que se respiraba en Atenas (Filócrates se había exiliado en el 343) es de suponer que su contenido sería muy diferente del de las dos anteriores. En cualquier caso, en la carta dirigida a Alejandro Isócrates se interesa por cuestiones más educativas que políticas, que pueden entenderse a la luz de su enfrentamiento con los académicos de Espeusipo. Este enfrentamiento con rivales de otras escuelas debió unirse por aquellas fechas a una descalificación de la política de Isócrates por parte de los sectores antimacedonios liderados por Demóstenes. Ante las críticas que se le dirigían desde diversos sectores, Isócrates empezó a escribir un discurso de reivindicación personal quizás con la intención de terminarlo para las Panateneas del 342. En él, omitiendo toda referencia a su vinculación con Filipo, tan inconveniente en aquel momento, el orador hacía una exaltación de los valores de la Atenas de sus antepasados que le permitía, por una parte demostrar su patriotismo y su amor a su ciudad (algo de lo que no podían hacer gala los miembros de la Academia), y por otra criticar la política de la Atenas contemporánea (dirigida por Demóstenes y con la que estaba en profundo desacuerdo) ${ }^{107}$. Una grave enfermedad tuvo durante tres años postrado a nuestro

107 La crítica a Esparta, que ocupa un amplio espacio en el Panatenaico, es instrumental en el discurso, tal como han advertido los estudiosos que la han analizado (cf. E.N. Tigerstedt, The Legend of Sparta in Classical Antiquity, Estocolmo 1965, vol. I, pp. 179-206 para las opiniones de Isócrates sobre Esparta). La finalidad de esa crítica no fue sin embargo la de resaltar por contraste las virtudes de Atenas, ya que, tal como vimos en la parte anterior de este estudio (cf. nota 1), Isócrates critica claramente la política de su ciudad. V. Gray, «Images of Sparta: writer and audience in Isocrates' Panathenaicus», en A. Powell - St. Hodkinson (eds.), The shadow of Sparta, Londres 1994, pp. 223-271, considera que Isócrates 
orador y al borde de la muerte, por lo que se vio incapacitado para trabajar y poner fin al Panatenaico. A este periodo de enfermedad, y ya comenzada la guerra con Atenas, pertenece la carta IV dirigida a Antípatro, lugarteniente de Filipo II. Se trata de una carta de recomendación, sin ninguna referencia a la situación política salvo una breve indicación al principio en la que Isócrates declara que es peligroso escribir a Macedonia en tiempos de guerra. El estilo de la carta no encaja con el de nuestro orador, por lo que considerando el tema de la carta y su enfermedad, no cabe descartar que otra persona participase en su redacción. Superada la enfermedad en el 339, cuando Atenas está en guerra con Macedonia, Isócrates publica el Panatenaico. Al año siguiente, en el 338, se produce la catástrofe de Queronea. Noticias alarmantes de la derrota llegan enseguida a la ciudad, que piensa que las tropas de Filipo se dirigen contra ella. Nuestro orador, viendo cómo sus proyectos de unidad entre los griegos han fracasado y las esperanzas que había depositado en Filipo se han desvanecido, no puede soportar ver el triste destino de su ciudad y se suicida dejando de ingerir alimentos ${ }^{108}$. A los pocos días muere y meses después se pronuncia su elogio fúnebre en los epitaphia ofrecidos a los caídos en Queronea. Nuestro orador no vivirá para comprobar que precisamente la derrota de Queronea fue la que posibilitó que Alejandro realizase la campaña contra el persa por la que él siempre había abogado.

concibió el discurso como un ensayo retórico con el que, partiendo de la alabanza a Atenas, pretendía plantear el problema de la mala recepción que tenían sus discursos críticos entre la audiencia contemporánea. Esta perspectiva, aunque correcta, es parcial porque ignora que las críticas a la Atenas contemporánea están en el núcleo del discurso y no se ven motivadas por su comparación con Esparta.

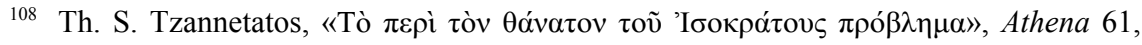
1957, pp. 289-322 contiene reflexiones interesantes acerca del modo en que se suicidó un Isócrates exhausto por los años y la enfermedad. No obstante, Tzannetatos intenta hacer compatible el optimismo de la carta III, que supone escrita por Isócrates pocos días después de Queronea (frente al testimonio de la propia carta, escrita sólo "después de la paz"), con el suicidio del orador. 